\title{
Progress of Drug-loaded Polymeric Micelles into Clinical Studies
}

Horacio Cabral $^{1}$ and Kazunori Kataoka ${ }^{1,2,3^{*}}$

${ }^{1}$ Department of Bioengineering, Graduate School of Engineering, The University of Tokyo, 73-1 Hongo, Bunkyo-ku, Tokyo 113-8656, Japan.

${ }^{2}$ Center for Disease Biology and Integrative Medicine, Graduate School of Engineering, The University of Tokyo, 7-3-1 Hongo, Bunkyo-ku, Tokyo 113-8656, Japan.

${ }^{3}$ Department of Materials Engineering, Graduate School of Engineering, The University of Tokyo, 7-3-1 Hongo, Bunkyo-ku, Tokyo 113-8654, Japan.

*Corresponding author

Prof. Kazunori Kataoka, PhD

kataoka@bmw.t.u-tokyo.ac.jp 


\begin{abstract}
Targeting tumors with long-circulating nano-scaled carriers is a promising strategy for systemic cancer treatment. Compared with free small therapeutic agents, nanocarriers can selectively accumulate in solid tumors through the enhanced permeability and retention (EPR) effect, which is characterized by leaky blood vessels and impaired lymphatic drainage in tumor tissues, and achieve superior therapeutic efficacy, while reducing side effects. In this way, drugloaded polymeric micelles, i.e. self-assemblies of amphiphilic block copolymers consisting of a hydrophobic core as a drug reservoir and a poly(ethylene glycol) (PEG) hydrophilic shell, have demonstrated outstanding features as tumor-targeted nanocarriers with high translational potential, and several micelle formulations are currently under clinical evaluation. This review summarizes recent efforts in the development of these polymeric micelles and their performance in human studies, as well as our recent progress in polymeric micelles for the delivery of nucleic acids and imaging.
\end{abstract}

Keywords: Polymeric micelles, clinical trials, anticancer drugs, gene delivery, ligand-mediated targeting 


\section{Introduction}

Cancer has become a leading cause of death, and the number of cancer patients is predicted to double by 2050 [1]. This situation is driving a rapid increase in the demand for effective cancer treatments, and the application of nanotechnology on cancer is expected to provide significant improvements for diagnosis, treatment and management of the disease, offering lower toxicity, specific targeting and reduced treatment cost. In this way, nano-scaled carriers, which can selectively deliver reporter molecules, anticancer drugs or genes to tumor tissues, have great potential for early and efficient diagnosis, and enhanced therapeutic efficacy [2-4]. The selectivity of nanocarriers to solid tumors is based on the augmented leakiness of neovascularization of malignant tissues to macromolecules, and the retention of these macromolecules due to the impaired lymphatic drainage in tumor tissues, so called the enhanced permeability and retention (EPR) effect [5]. Thus, the in vivo success of such nanocarriers relies on their stability while circulating in the body, avoiding recognition by the reticuloendothelial system, as well as their effective extravasation and penetration in tumor tissues for selectively releasing their payloads [2-4].

Since the late 1980s, our group has been developing self-assembled polymeric micelles as carrier systems for delivering various bioactive molecules, such as cytostatic agents, nucleic acids, reporter molecules, for cancer diagnosis and therapy (Figure 1). Our polymeric micelles are prepared by self-assembly of poly(ethylene glycol)-b-poly(amino acid) copolymers into core-shell nanostructures [4,6], where the core is formed by the poly(amino acid) segment, which is engineered for efficiently incorporating and releasing the payload, and the poly(ethylene glycol) (PEG) block forms a dense and soft hydrophilic shell, which protects the drugs in the core, hindering the interaction with plasma proteins and cells, avoiding the recognition by macrophages and prolonging the circulation in the bloodstream [4,6]. The diameter of polymeric micelles resembles that of natural viruses and can be tuned from 10 to $100 \mathrm{~nm}[4,6]$, which reduces their accumulation in the organs of the reticuloendothelial system and facilitates overcoming physiological barriers, such as lymphatic transport to lymph nodes after intradermal injection [7], and extravasation, deep penetration and high accumulation in solid tumors after systemic injection (Figure 2) [8]. This broad and increased accumulation of polymeric micelles in tumor tissues augment the efficacy of the incorporated drugs, allowing the delivery of therapeutic concentrations of drugs to most cells within tumors $[4,6,8]$. Moreover, after accumulating in tumors, polymeric micelles can act as intracellular Trojan horses, selectively delivering the drugs to their subcellular targets, thus, overcoming mechanisms of drug resistance and enhancing the efficiency of therapies $[4,6,9]$. In addition, after releasing their cargo, micelles can dissociate into the former block copolymers and be eliminated by filtration through kidneys, avoiding any long-term side effect $[4,6]$. 
Our polymeric micelles incorporating doxorubicin (Dox; NK911, Nippon Kayaku, Co.) were the first to proceed into clinical evaluation in 2001 [10], and soon after, several other micelle formulations loading anticancer agents joined human trials (Table 1). These clinical studies are demonstrating high efficacy of polymeric micelles even against intractable tumors, such as triplenegative breast cancer and pancreatic cancer, and the reduction of side effects associated with the incorporated drugs [11]. In this article, we have reviewed the works for developing these micelles systems and their recent clinical performance. Moreover, we have also included our recent progress and preclinical observations on polymeric micelles for nucleic acid delivery and imaging, as well as the impact of ligand installation on the targeting efficiency of micelles.

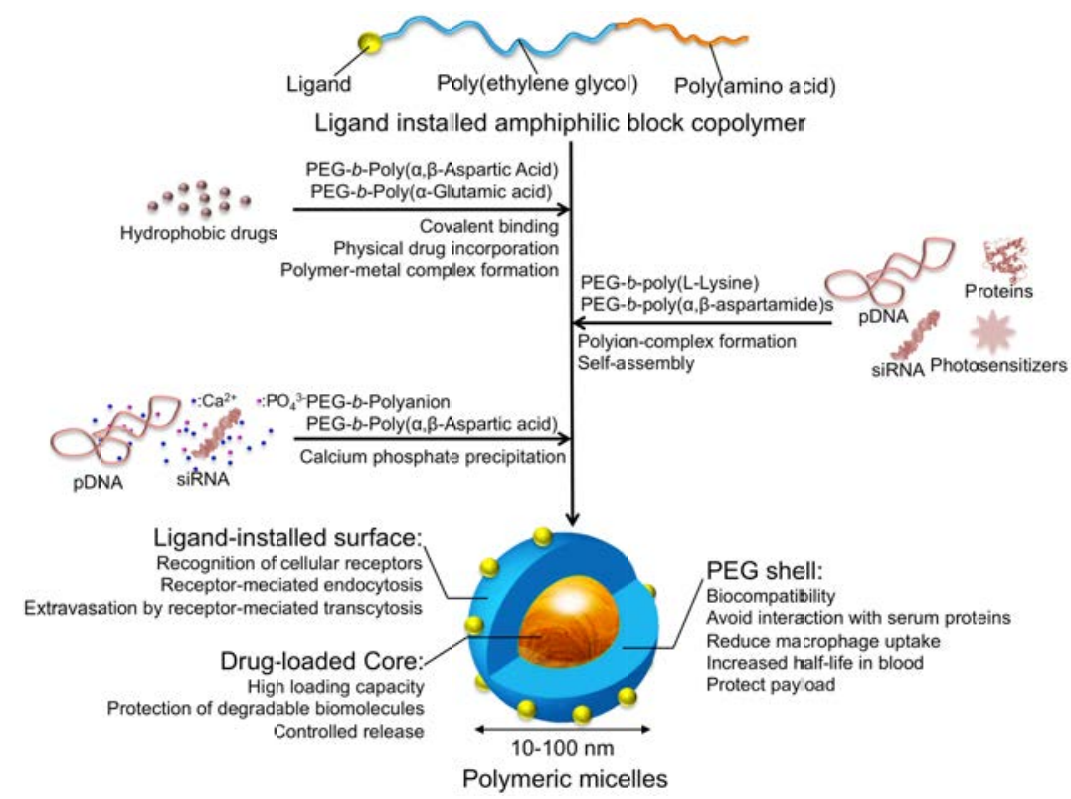

Figure 1. Self-assembled polymeric micelles from PEG-b-poly(amino acid) copolymers represent a versatile platform for incorporating various bioactive molecules through the controlled interaction of the payloads and the core-forming segments. The relative small size and the PEG shell are remarkable advantages for operating at the biological interface. 


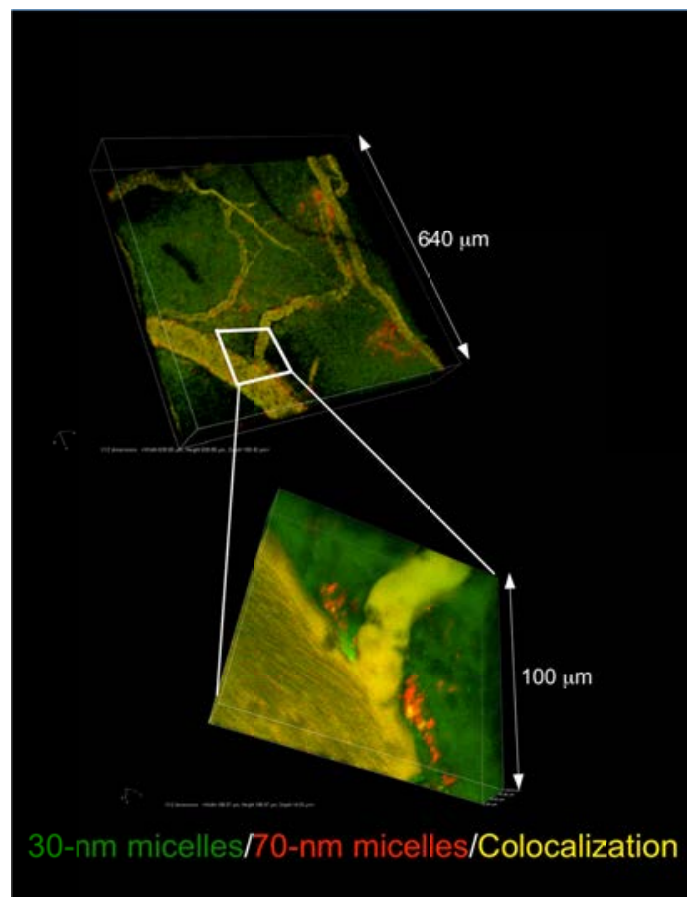

Figure 2. In vivo real-time microscopy of fluorescent polymeric micelles with $30-\mathrm{nm}$ (green) and 70-nm (red) diameters in poorly permeable pancreatic tumours. Z-stack volume reconstruction of the tumours $1 \mathrm{~h}$ after co-injection of the fluorescent micelles and magnification of the perivascular region (indicated by a white trapezium). Colocalization of both micelles in the blood vessels is observed as yellow. While 70-nm micelles remained at perivascular regions, only 30-nm micelles achieved extravasation and deep penetration in tumor tissues. The relative small size of polymeric micelles is a considerable advantage for overcoming biological barriers. Reprinted with permission from reference [8].

Table 1. Current clinical status of polymeric micelles based on PEG-b-poly(amino acid) copolymers

\begin{tabular}{|c|c|c|c|c|c|c|c|c|}
\hline Name & Drug & $\begin{array}{l}\text { Block } \\
\text { copolymer }\end{array}$ & $\begin{array}{l}\text { Drug } \\
\text { loading } \\
\text { (\%w drug/w } \\
\text { polymer) }\end{array}$ & $\begin{array}{l}\text { Size } \\
(\mathbf{n m})\end{array}$ & Company & $\begin{array}{l}\text { Development } \\
\text { phase }\end{array}$ & Indication & References \\
\hline NK105 & Paclitaxel & $\begin{array}{l}\text { PEG- } b- \\
\operatorname{poly}(\alpha, \beta- \\
\text { aspartic acid })\end{array}$ & 23 & 85 & $\begin{array}{l}\text { Nippon } \\
\text { Kayaku, Co. }\end{array}$ & $\begin{array}{l}\text { Phase III } \\
\text { (started July } \\
\text { 2012; breast } \\
\text { cancer) }\end{array}$ & $\begin{array}{l}\text { Gastric } \\
\text { cancer/ } \\
\text { Breast } \\
\text { cancer }\end{array}$ & $32-34$ \\
\hline NK012 & SN-38 & $\begin{array}{l}\text { PEG-b-poly(L- } \\
\text { glutamic acid) }\end{array}$ & 20 & 20 & $\begin{array}{l}\text { Nippon } \\
\text { Kayaku, Co. }\end{array}$ & Phase II & $\begin{array}{l}\text { Triple } \\
\text { negative } \\
\text { breast } \\
\text { cancer }\end{array}$ & $36,38-48$ \\
\hline NK911 & Doxorubicin & $\begin{array}{l}\text { PEG-b- } \\
\operatorname{poly}(\alpha, \beta- \\
\text { aspartic acid })\end{array}$ & 17 & 40 & $\begin{array}{l}\text { Nippon } \\
\text { Kayaku, Co. }\end{array}$ & Phase II & $\begin{array}{l}\text { Various } \\
\text { solid } \\
\text { tumors }\end{array}$ & 11,22 \\
\hline $\begin{array}{l}\mathrm{NC}- \\
6004\end{array}$ & Cisplatin & $\begin{array}{l}\text { PEG-b-poly(L- } \\
\text { glutamic acid) }\end{array}$ & 30 & 20 & $\begin{array}{l}\text { Nanocarrier, } \\
\text { Co. }\end{array}$ & $\begin{array}{l}\text { Phase III } \\
\text { (started } \\
2013 \text { ) }\end{array}$ & $\begin{array}{l}\text { Pancreatic } \\
\text { cancer }\end{array}$ & $57,62-66$ \\
\hline $\begin{array}{l}\mathrm{NC}- \\
4016\end{array}$ & Oxaliplatin & $\begin{array}{l}\text { PEG-b-poly(L- } \\
\text { glutamic acid) }\end{array}$ & 30 & 30 & $\begin{array}{l}\text { Nanocarrier, } \\
\text { Co. }\end{array}$ & Phase I & $\begin{array}{l}\text { Various } \\
\text { solid } \\
\text { tumors }\end{array}$ & $58,67-71$ \\
\hline $\begin{array}{l}\mathrm{NC}- \\
6300\end{array}$ & Epirubicin & $\begin{array}{l}\text { PEG- } b \text { - } \\
\text { poly(aspartate- }\end{array}$ & 20 & 60 & $\begin{array}{l}\text { Nanocarrier, } \\
\text { Co. }\end{array}$ & Phase I & $\begin{array}{l}\text { Various } \\
\text { solid }\end{array}$ & 52,53 \\
\hline
\end{tabular}




\begin{tabular}{|c|c|c|c|c|c|c|c|c|}
\hline & & hydrazone) & & & & & tumors & \\
\hline $\begin{array}{l}\text { siRNA } \\
\text { micelles }\end{array}$ & siRNA & $\begin{array}{l}\text { PEG- } b- \\
\text { polycations }\end{array}$ & Various & $40-60$ & $\begin{array}{l}\text { Nanocarrier, } \\
\text { Co. }\end{array}$ & Preclinical & - & $\begin{array}{l}87,93,95,96 \\
99-109\end{array}$ \\
\hline
\end{tabular}

\section{Polymeric micelles in clinical trials}

\subsection{Doxorubicin (Dox)-loaded micelles (NK911)}

Dox is a potent anthracycline widely used for the treatment of several malignancies, but presents serious adverse effects, such as heart damage, which restrict the working dosage [12]. Several carrier approaches have been considered for delivering Dox to solid tumors, including N(2-hydroxypropyl)methacrylamide (HPMA) copolymers covalently conjugating Dox via enzymatically cleavable glycyl-phenylalanyl-leucyl-glycine spacers [13], which was the first polymeric drug conjugate to proceed into clinical trials (PK1) [14], Dox-loaded liposomes (Myocet) and PEGylated Dox-loaded liposomes (Doxil/Caelix), which have been approved by the US Food and Drug Administration (FDA) for the treatment of Kaposi's sarcoma [15], and ovarian [16] and breast cancer [17]. Our polymeric micelles incorporating Dox were originally developed in the late 1980 s by using PEG- $b$-poly( $\alpha, \beta$-aspartic acid) copolymer conjugated with Dox through amide bonds (Figure 3A), which was engineered for physically entrapping Dox via $\pi-\pi$ stacking $[18,19]$. Thus, the physically loaded Dox serves as an agglomerant in the core of micelles, augmenting the stability of the micelles and reducing the critical micelle concentration, allowing the preservation of the micelles upon dilution. Moreover, because Dox can self-associate into dimers [20], these micelles not only incorporated Dox monomers, but also Dox dimers, which were found to further stabilize the micellar nanostructure [21]. However, because these dimers are not clinically approved, the micelle formulation was optimized to include only Dox monomers, while mantaining their high stability in blood and high antitumor efficacy [22]. In preclinical studies, these micelles showed longer blood circulation, with a 29-fold higher area under the drug concentration versus time curve (AUC) in plasma than free Dox, and higher accumulation in tumors due to the EPR effect (3.4-fold higher than that of free DOX), leading to a stronger antitumor effect than the free drug in mice models of sarcoma and lung, breast, and colon cancer [22]. This optimized formulation were the first micelles to proceed into clinical trials under the name NK911 in 2001 (Figure 3B). 


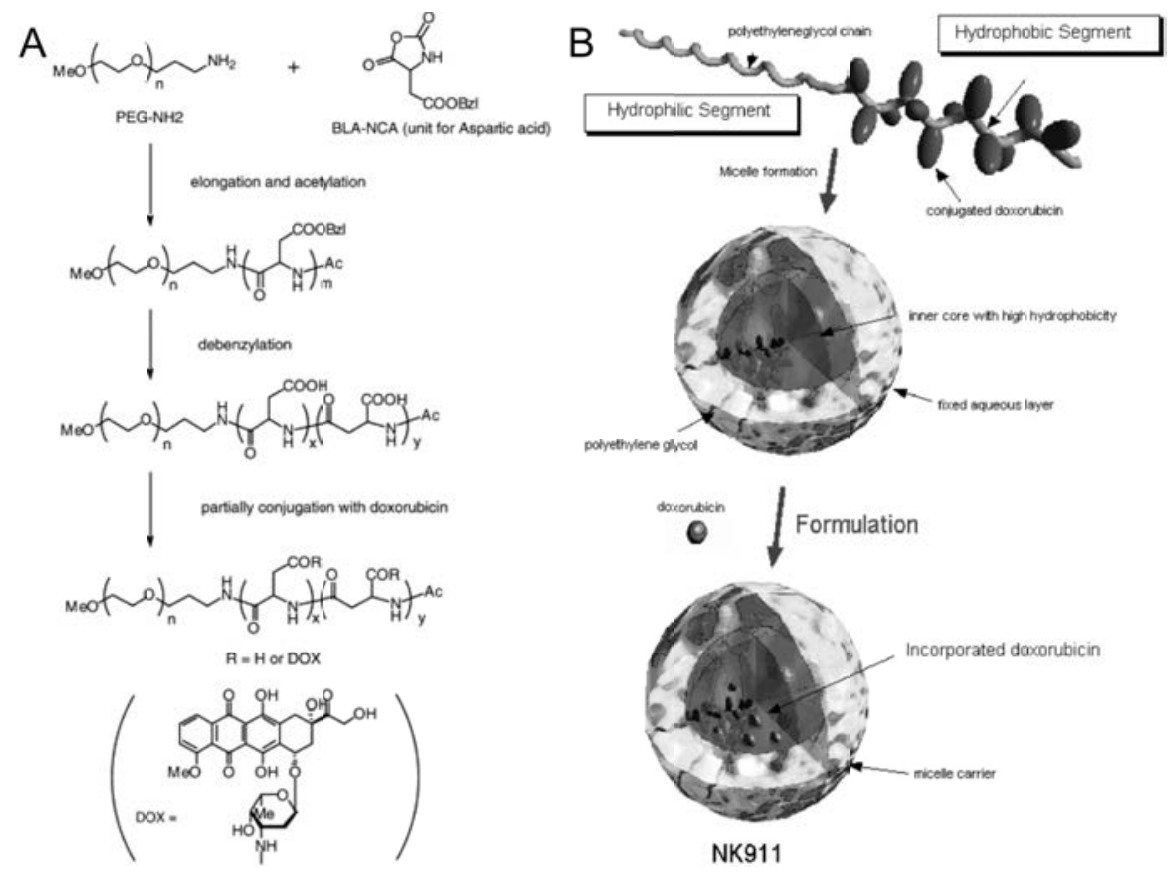

Figure 3. A. Preparation of PEG- $b$-poly $(\alpha, \beta$-aspartic acid-doxorubicin) copolymer. PEG- $b$ $\operatorname{poly}(\alpha, \beta$-aspartic acid) was prepared by the ring-opening polymerization of the $\mathrm{N}$ carboxyanhydride of benzyl-L-aspartate, followed by the debenzylation under basic conditions. Dox was conjugated to the block copolymer via amide bonds. B. Self-assembly of NK911 in aqueous conditions by stable physical incorporation of free doxorubicin within the hydrophobic core of poly $(\alpha, \beta$-aspartic acid-doxorubicin). Reprinted with permission from reference [11]

Phase I clinical trials of NK911 in 23 patients with solid tumors were performed at the National Cancer Center Hospital, Tokyo, Japan [11]. This study specified the toxicity profile, maximum-tolerated dose (MTD), the pharmacokinetics and the recommended dose of intravenously administered NK911. The administration schedule was once every 3 weeks using an infusion pump at a rate of $10 \mathrm{mg} \mathrm{min}^{-1}$ of Dox equivalent. The results showed that NK911 was well tolerated, producing only moderate nausea and vomiting at Dox dosages usually causing myelosuppression, and infusion-related reactions were not observed. The predominant haematological toxicity was neutropenia at $67 \mathrm{mg} \mathrm{m}^{-2}$, while non-haematological toxicities, such as alopecia, stomatitis, and anorexia, were mild. The recommended dose was determined to be $50 \mathrm{mg} \mathrm{m}^{-2}$ every 3 weeks and the MTD was $67 \mathrm{mg} \mathrm{m}^{-2}$ due to grade 4 neutropenia. The plasma AUC of the NK911 at the recommended dose $\left(3.2 \mu \mathrm{g} \mathrm{h} \mathrm{m}^{-1}\right)$ was higher than that of free Dox $\left(1.6 \mu \mathrm{g} \mathrm{h} \mathrm{ml}^{-1}\right)$ (Table 2), but lower than Dox-loaded PEGylated liposomes (902 $\mu \mathrm{g} \mathrm{h} \mathrm{ml} \mathrm{h}^{-1}$ ), probably because PEGylated liposomes do not release the encapsulated Dox [23]. In addition, one partial response was observed in a patient with metastatic pancreatic cancer [11]. This clinical trial established valuable criteria for studying drug-loaded polymeric micelles in humans, while the translational success of NK911 
provided a philosophy for constructing micelles for clinical application. NK911 micelles have proceeded into Phase II clinical trials against metastatic pancreatic cancer, but the observations have not been reported so far.

Table 2. Pharmacokinetic parameters for drug-loaded polymeric micelles in clinical trials and the free drugs.

\begin{tabular}{|c|c|c|c|c|c|c|c|c|}
\hline \multirow{3}{*}{$\begin{array}{c}\text { Pharmacokinetic } \\
\text { parameter }\end{array}$} & \multicolumn{8}{|c|}{ Formulation } \\
\hline & \multicolumn{2}{|c|}{ NK911 [11] } & \multicolumn{2}{|c|}{ NK105 [33] } & \multicolumn{2}{|c|}{ NK012 [45] } & \multicolumn{2}{|c|}{ NC-6004 } \\
\hline & $\begin{array}{l}\text { Free } \\
\text { doxorubicin }\end{array}$ & Micelles & $\begin{array}{l}\text { Free } \\
\text { paclitaxel }\end{array}$ & Micelles & Free SN-38 & Micelles & $\begin{array}{l}\text { Free } \\
\text { cisplatin } \\
{[113,114]}\end{array}$ & Micelles [65] \\
\hline $\operatorname{Dose}^{\mathrm{a}}\left(\mathrm{mg} \mathrm{m}^{-2}\right)$ & 50 & 50 & 210 & 150 & 28 & 28 & $80-100$ & 90 \\
\hline $\mathrm{t}_{1 / 2}(\mathrm{~h})$ & $2.4 \pm 0.9$ & $7.5 \pm 0.7$ & $13.3 \pm 1.5$ & $10.6 \pm 1.3$ & $209 \pm 25$ & $137 \pm 19$ & 0.5 & $129 \pm 40$ \\
\hline $\begin{array}{l}\mathrm{AUC}_{0 \text {-inf }}{ }^{\mathrm{b}} \\
\left(\mu \mathrm{h} \mathrm{ml}^{-1}\right)\end{array}$ & $1.62 \pm 1$ & $3.2 \pm 0.4$ & $23.1 \pm 10.6$ & $369.8 \pm 35.2$ & $2.1 \pm 0.8$ & $294 \pm 62$ & $45.8 \pm 4.6$ & $2836 \pm 554$ \\
\hline $\begin{array}{l}\text { Maximum } \\
\text { concentration in } \\
\text { blood }\left(\mu \mathrm{g} \mathrm{ml}^{-1}\right)\end{array}$ & N.A. & $3.9 \pm 0.7$ & $6.7 \pm 2.7$ & $40.17 \pm 5.5$ & $0.1 \pm 0.03$ & $19.1 \pm 3.9$ & $3.3 \pm 0.3$ & $60.8 \pm 12.5$ \\
\hline $\begin{array}{l}\text { Volume of } \\
\text { distribution } \\
\left(\mathrm{ml} \mathrm{m}^{-2}\right)\end{array}$ & $\begin{array}{l}930000 \pm 46666 \\
6^{\mathrm{d}}\end{array}$ & $\begin{array}{l}579444 \pm 1400 \\
00^{\mathrm{d}}\end{array}$ & $\begin{array}{l}58900 \pm \\
24700\end{array}$ & $4527 \pm 639$ & N.A. & $2020 \pm 530$ & 12000 & $6.5 \pm 3.8^{\mathrm{d}}$ \\
\hline $\begin{array}{l}\text { Total clearance } \\
\left(\mathrm{ml} \mathrm{h}^{-1} \mathrm{~m}^{-2}\right)\end{array}$ & $864 \pm 336$ & $402 \pm 66$ & $\begin{array}{l}10740 \pm 486 \\
0\end{array}$ & $408.6 \pm 37.3$ & N.A. & $98.8 \pm 20.6$ & $\begin{array}{l}20700 \pm 582 \\
0\end{array}$ & $33.8 \pm 11.1^{\mathrm{d}}$ \\
\hline
\end{tabular}

\footnotetext{
${ }^{\mathrm{a}}$ Recommended dose for micelles

${ }^{\mathrm{b}} \mathrm{AUC}_{0 \text {-inf }}$ : area under concentration-time curve from zero to infinity

${ }^{\mathrm{c}}$ At steady state

${ }^{\mathrm{d}}$ Calculated by considering the body surface area of patients as $1.8 \mathrm{~m}^{2}$
}

\subsection{Paclitaxel (Ptx)-loaded polymeric micelles (NK105)}

The development of polymeric micelles incorporating paclitaxel (Ptx) was also considered, as Ptx presents high clinical efficacy against several malignancies, including lung, breast, ovarian, head and neck cancer, and Kaposi's sarcoma [24], but it is poorly soluble in water, compelling its administration by mixing with ethanol and Kolliphor EL, which is associated with allergic reactions. Moreover, Ptx present neutropenia and neurotoxicity at clinically relevant doses, the latter being a significant dose-limiting toxicity, as there are no effective therapies to prevent or reduce Ptxinduced nerve damage [24]. Various drug carriers have been considered for improving solubility and reducing side effects, as well as enhancing the delivery of Ptx to solid tumors [25]. Among them, albumin nanoparticles containing Ptx (Abraxane) have recently received clinical approval for the treatment of breast, lung and pancreatic cancer [26,27], paclitaxel-conjugated poly(glutamic acid) [28] (Opaxio) is being studied in Phase III for patients with advanced ovarian cancer (NCT00108745), and micelles from PEG-b-poly(d,l-lactide) copolymer incorporating Ptx in their hydrophobic core [29] (Genexol-PM) have been clinically approved in Bulgaria, Hungary and South Korea, and are being evaluated in Phase II trials in the US.

From our observations on Dox-loaded polymeric micelles and NK911, we have noted that tailoring the cohesive forces between the polymer strands and the incorporated drugs is essential for 
preparing micelles capable of tolerating dilution and harsh conditions during blood circulation. Using PEG-b-poly(amino acid) copolymers is a clear advantage for formulating stable drug-loaded polymeric micelles, as the poly(amino acid) segments can stabilize the nanostructure by hydrogen bonding with the incorporated drugs, as well as between the poly(amino acid) chains, while the side groups of the poly(amino acid) block can be easily modified with moieties having high affinity with physically incorporated drugs. The latter was firstly confirmed by preparing Dox-loaded polymeric micelles from PEG-b-poly(benzyl-L-aspartate) copolymer [30], where the poor water solubility of the core-forming block and $\pi-\pi$ stacking of benzyl residues with Dox allowed the formation of micelles with considerable stability in blood and enhanced tumor accumulation by EPR effect [31]. For constructing long-circulating Ptx-loaded polymeric micelles (NK105; Nippon Kayaku, Co.), the side groups of the poly(amino acid) segment were engineered for enhancing the affinity of the hydrophobic backbone of the copolymer with Ptx [32]. Thus, 4-phenyl-1-butanol was conjugated to half of the carboxylic groups of PEG- $b$-poly $(\alpha, \beta$-aspartic acid) copolymer. The resulting PEG- $b$ poly(aspartate-4-phenyl-1-butanolate) copolymer was mixed with Ptx in dichloromethane and dispersed in water as an emulsion. After evaporation of dichloromethane, the block copolymers self-assembled into core-shell polymeric micelles with $85-\mathrm{nm}$ diameter, physically incorporating Ptx in their core. Preclinical pharmacokinetics studies of NK105 showed that the plasma AUC of the Ptx in the micelles was 50-fold higher than that of Ptx [32], while the tumor AUC of NK105 in a subcutaneous human adeocarcinoma tumor model (HT-29) was 25-fold higher than that of Ptx [32]. Moreover, intravenously injecting NK105 once-a-week for 3 weeks at $100 \mathrm{mg} \mathrm{kg}^{-1}$ on a Ptxbase exhibited superior antitumor activity and less toxicity than Ptx in the HT-29 model [32]. In addition, no neurotoxicity was detected after single intravenous injection of NK105 at $7.5 \mathrm{mg} \mathrm{kg}^{-1}$ because of the limited access of micelles to nervous tissues, while the same dose of Ptx caused degeneration of myelinated fibres and a marked neurotoxicity [32].

NK105 advanced into Phase I clinical studies to determine the MTD, dose limiting toxicities and recommended dose, as well as NK105 pharmacokinetics (Table 2), in 19 patients with various cancers (pancreatic, bile duct, gastric and colon) [33]. NK105 was provided as a freeze-dried formulation containing approximately $23 \%$ of $\mathrm{Ptx}$ in weight, which was reconstituted and administered by infusion for $1 \mathrm{~h}$ every 3 weeks without antiallergic premedication, starting with 10 mg Ptx equivalent $\mathrm{m}^{-2}$. Accordingly, the MTD was found to be $180 \mathrm{mg} \mathrm{m}^{-2}$, with Grade 4 neutropenia being the dose limiting toxicity ( 2 patients), and only 1 allergic reaction. Moreover, one pancreatic cancer patient, receiving more than 12 cycles of NK105, experienced a partial response, while patients with colon and gastric cancer showed stable disease for ten and seven cycles, respectively. From this study, the recommended dose for Phase II studies was $150 \mathrm{mg} \mathrm{m}^{-2}$. It is interesting to note that at this dose the plasma AUC of NK105 $\left(369.8 \mu \mathrm{g} \mathrm{h} \mathrm{ml}^{-1}\right)$ was not only 15- 
fold higher than that of conventional Ptx dosage, but also 33-fold larger than that of Genexol-PM $\left(11.5 \mu \mathrm{g} \mathrm{h} \mathrm{ml}^{-1}\right)$ at a dose of $300 \mathrm{mg} \mathrm{m}^{-2}$ (Table 2) [33]. However, it was not possible to determine the extent of released Ptx and NK105-incorporated Ptx in the bloodstream, since the equilibrium between both forms could not be maintained during the process of separation from blood [33]. Moreover, the maximum concentration in plasma of NK105 $\left(40.1 \mu \mathrm{g} \mathrm{ml}^{-1}\right.$ at $\left.150 \mathrm{mg} \mathrm{m}^{-2}\right)$ was much higher than that of Genexol-PM $\left(3.1 \mu \mathrm{g} \mathrm{ml}^{-1}\right.$ at $\left.300 \mathrm{mg} \mathrm{m}^{-2}\right)$ and the total plasma clearance for NK105 (408.6 $\mathrm{ml} \mathrm{h}^{-1} \mathrm{~m}^{-2}$ ) was more than 70-fold slower than Genexol-PM $\left(29,300 \mathrm{ml} \mathrm{h}^{-1} \mathrm{~m}^{-2}\right)$, suggesting that tailoring the affinity of Ptx with the core-forming blocks of NK105 effectively enhanced their stability during circulation in the bloodstream.

A Phase II study of NK105 started in 2007, and 57 patients having measurable disease and one chemotherapeutic regimen, except taxane, enrolled. NK105 was administered at the recommended dose (150 $\mathrm{mg}$ of Ptx equivalent $\mathrm{m}^{-2}$ ) [34]. Thus, the best overall response rate (ORR) of NK105, which was defined as the proportion of patients whose response is either complete response or partial response, accounted for $25 \%$ with two complete responses in gastric cancer patients and 12 partial responses. Moreover, 17 patients showed stable disease and the median overall survival was 14.4 months. The most common Grade 4 haematological toxicity was neutropenia (14 patients; $24.6 \%$ ), while neurotoxicity was mainly Grade $1(64.9 \%)$, which is a major advantage for the management of paclitaxel-induced side effects. The acceptable activity and good tolerability for NK105 in this Phase II trial encouraged a multi-national Phase III study for comparing NK105 with paclitaxel in patients with metastatic as well as recurrent breast cancer (NCT01644890) to clarify the survival and therapeutic benefits of NK105.

\subsection{SN-38-loaded polymeric micelles (NK012)}

From our initial Dox-loaded micelles, we have also learned that amphiphilic block copolymers conjugating hydrophobic drugs in the core-forming blocks can assemble polymeric micelles in aqueous environment without the addition of free drug molecules. Even though the amide bond used to conjugate Dox and poly( $\alpha, \beta$-aspartic acid) in NK911 cannot be cleaved [11], the linkage between the drug and the polymer can be selected to dissociate at desired conditions, specifically releasing the drug. In this way, polymeric micelles encapsulating the active metabolite of the widely used topoisomerase I inhibitor irinotecan, i.e. 7-ethyl-10-hydroxy-CPT (SN-38), which is approximately 1000-fold more active than irinotecan [35], were prepared by conjugating SN-38 to PEG-b-poly(L-glutamic acid) by esterification of the phenol group of SN-38 and the carboxylate moieties of the poly(L-glutamic acid) segment [36]. The SN-38 conjugated block copolymers self-assembled in aqueous conditions into polymeric micelles with 20 -nm diameter. The ester bond within the core of the micelles can be cleaved in phosphate buffered saline, releasing 
approximately $57 \%$ of the conjugated SN-38 from the micelles after $24 \mathrm{~h}$ incubation at $37^{\circ} \mathrm{C} \mathrm{[36].}$ Moreover, SN-38-loaded micelles are effectively stabilized in physiological conditions by the extremely low solubility of SN-38 in water (approximately $80 \mathrm{ng} / \mathrm{mL}$ ) and the strong tendency of the drug for $\pi-\pi$ stacking [37].

Pharmacokinetics studies revealed that, in mice bearing subcutaneous HT-29 xenografts, for NK012 injected at $30 \mathrm{mg} \mathrm{kg}^{-1}$, the plasma AUC was 5,010 $\mathrm{g} \mathrm{h} \mathrm{m}^{-1}$, while for irinotecan at 66.7 $\mathrm{mg} \mathrm{kg}{ }^{-1}$ the AUC was $0.022 \mu \mathrm{g} \mathrm{h} \mathrm{ml}^{-1}$, and $0.001 \mu \mathrm{g} \mathrm{h} \mathrm{ml}{ }^{-1}$ for the metabolized SN-38 from irinotecan [36], indicating the enhanced prolonged blood circulation of the micelles. Due to this prolonged life in the bloodstream, SN-38-loaded micelles (NK012; Nippon Kayaku, Co.) demonstrated effective delivery of high drug levels in several tumor xenografts, including models of glioma [38] as well as renal [39], colon [36], gastric [40], and pancreatic cancer [41,42], showing significant antitumor activity. The superior acumulation and activity of NK012 in poorly vascularized pancreatic tumors (Capan1) [41] can be related to their relatively small size, as we have recently demonstrated that the sub-50 nm diameter of drug-loaded micelles was a substantial advantage for achieving deep penetration and high drug concentrations in poorly permeable tumors [8]. Fluorescence microscopies of Capan1 tissues demonstrated that irinotecan/SN-38 was rapidly cleared $1 \mathrm{~h}$ after injection, while NK012 was detected for more than $96 \mathrm{~h}$, maintaining the intratumoral levels of SN-38 for more than 3 days, without the need of enzymatic conversion of irinotecan. Moreover, NK012 effectively suppressed the growth of metastases in models of lung metastasis from renal tumors [39] and peritoneal metastasis from gastric tumors [40], significantly prolonging survival compared with irinotecan. Combination of NK012 with 5-fluoruracil (5-FU) [43] for the treatment of colorectal cancer, and cisplatin for the treatment of small cell lung cancer (SCLC) [44] have also shown to improve the efficacy of the treatment, expanding the therapeutic potential of NK012 for both monotherapy and combination therapy.

NK012 was studied in two independent Phase I clinical trials, one at the National Cancer Center in Japan for NK012 as monotherapy [45], and another at Sarah Canon Cancer Center in the US for the combination of NK012 with 5-FU [46], to define the MTD, dose limiting toxicities, and recommended dose. NK012 were reconstituted from a freeze-dried formulation containing $20 \%$ of SN-38 in weight. Then, NK012 were intravenously infused for $1 \mathrm{~h}$ every 3 weeks until disease progression or unacceptable toxicity happened. Both the Japanese and the US study showed similar pharmacokinetics, showing a plasma AUC of approximately $294 \mu \mathrm{g} \mathrm{h} \mathrm{ml} \mathrm{m}^{-1}$ (Table 2). The elimination of NK012 into urine by renal clearance was difficult determine because SN-38 is released from PEG-b-poly(L-glutamic acid) in urine. Instead the total amount of SN-38 in urine was determined after alkali treatment [45]. NK102 showed considerably lower total clearance and volume of distribution at steady state than irinotecan [47], suggesting the sufficient stability of the 
micelles after systemic administration and their low distribution to normal tissue.. The MTD of NK012 was $37 \mathrm{mg} \mathrm{m}^{-2}$, and the dose limiting toxicity was neutropenia. The studies also showed 3 partial responses in patients with triple negative breast cancer, 1 partial response in a patient with esophageal cancer and 1 partial response in a patient with SCLC. The recommended dose for the Phase II clinical studies was $28 \mathrm{mg} \mathrm{m}^{-2}$. Moreover, a Phase I/II study of NK012 in patients with multiple myeloma (JapicCTI-111652) has been recently started in Japan. In addition, as NK012 have demonstrated synergistic effect when combined with 5-FU and platinum drugs in mouse tumor models $[43,44]$, a Phase I study of NK012 and carboplatin has been recently completed in patients with solid tumors, expanding the dose in patients with triple negative breast cancer (NCT01238952), and a Phase I trial of NK012 combined with 5-FU and leucovorin (LV) is ongoing in patients with advanced solid tumors, with a dose expansion phase in patients with metastatic colorectal cancer (NCT01238939).

Because of the safety and antitumor activity demonstrated in the Phase I studies, a Phase II trial was performed at the Sarah Canon Cancer Center to evaluate NK012 as monotherapy in patients with SCLC [48]. Patients were divided in 2 groups, namely sensitive relapsed, which have responded to first line therapy within 90 days, and refractory relapsed, which have showed no response to the first line therapy for more than 90 days. NK012 mainly exhibited positive efficacy in patients with sensitive relapsed SCLC with 2 complete responses, 22\% ORR, and 68\% of ORR plus stable disease, and the micelles were well tolerated, with neutropenia being the prevalent grade 3/4 toxicity (44\%). These moderate activity and tolerability of NK012 have stimulated other Phase II trials for NK012, and studies are underway in the US for patients with locally advanced nonresectable and metastatic breast cancer patients with triple negative phenotype (NCT00951054), as well as in Japan for patients with unresectable advanced colorectal cancer, who have failed previous oxaliplatin-based chemotherapies (JapicCTI-090780).

\subsection{Epirubicin-loaded micelles (NC-6300)}

Besides the amide bond between Dox and PEG- $b$-poly( $\alpha, \beta$-aspartic acid) in NK911, the linkage between Dox and the block copolymers can also be designed to be cleaved under specific conditions by using a labile linkage, allowing the preparation of micelles capable of releasing Dox after cellular uptake. As polymeric micelles are internalized by endocytosis, the conditions within the endocytic vesicles can be used to trigger drug release from the micelles for intracellularly delivering their cargo and enhancing drug efficiency. Endosomes progress from early to late endosomes to lysosomes as they move toward the cell nucleus, changing their inner $\mathrm{pH}$ from 6.5 to 5.0 [49], which can be used as a significant stimulus for specific activation of drug release since the $\mathrm{pH}$ in the bloodstream and healthy tissues is 7.4. Therefore, $\mathrm{pH}$-sensitive Dox-loaded micelles were 
constructed by conjugating Dox to PEG- $b$-poly $(\alpha, \beta$-aspartic acid) via a hydrazone bond [50]. These micelles were shown to selectively release the drug at acidic $\mathrm{pH}$, while at extracellular $\mathrm{pH}$, i.e. $\mathrm{pH}$ 7.4, the release was negligible. The prevention of drug release at $\mathrm{pH} 7.4$ and the selective accumulation of these micelles in tumor tissues allowed increasing the MTD in mice 4-fold (40 mg $\mathrm{kg}^{-1}$ injected intravenously 3 times every 4 days) compared to free Dox (10 mg kg ${ }^{-1}$, similar schedule). Moreover, the enhanced delivery of Dox to tumors significantly suppressed the growth of subcutaneous C26 tumors [51].

To take this system to the clinical stage, Dox was changed to Epirubicin (Epi), the 4'-epimer of Dox, because Epi has lower cardiotoxicity than Dox, while both drugs show similar efficacy, and the formulation was optimized to achieve enhanced stability after systemic injection, prolonged blood circulation and improved therapeutic efficacy [52]. Thus, PEG-b-poly(aspartate) copolymers were partially substituted with hydrophobic benzyl groups for stabilizing the micellar structure and approximately 10 Epi molecules were conjugated to one block copolymer through hydrazone bonds [52,53]. These pH-sensitive Epi-loaded micelles (NC-6300; Nanocarrier, Co.) showed prolonged blood circulation and negligible drug release in the bloodstream. NC-6300 also delivered significant amounts of Epi to tumor tissues and approximately half of the Epi delivered from the micelles was found as free drug, i.e. released from the micelles, inside the tumors $24 \mathrm{~h}$ after administration. Regarding the distribution of NC-6300 to other tissues, some percentage of the injected dose was found in liver $24 \mathrm{~h}$ after injection. However, changes in hepatic parameters in mice after receiving $20 \mathrm{mg} / \mathrm{kg}$ of NC-6300 in an Epi base were negligible and temporary. NC-6300 also displayed superior antitumor activity than Epi in models of human hepatocellular carcinoma and breast cancer, efficiently restricting the growth rate of tumors. Moreover, 9 doses of NC-6300 at $10 \mathrm{mg} \mathrm{kg} \mathrm{gver}^{-1}$ 12 weeks did not affect the cardiac function of mice, while free Epi at similar dosing schedule significantly deteriorated heart conditions $[52,53]$. These positive preclinical results stimulated the study of NC-6300 in the clinical stage, and a Phase I study has started in September 2013 to investigate the safety, tolerability and recommended dosage, and if possible, to determine the efficacy of NC-6300 in patients suffering from advanced or metastatic solid tumors.

\subsection{Platinum drug-loaded polymeric micelles}

Platinum anticancer drugs are a major component in chemotherapy regimes. Cisplatin is used for the treatment of myelomas, lymphomas and melanoma, as well as testicular, ovarian, head and neck, bladder and lung cancers [54]. Oxaliplatin, oxalato(trans-l-1,2diaminocyclohexane)platinum(II), was approved by the US FDA in 2004 for the first-line treatment of advanced colorectal cancer in combination with 5-FU and LV, significantly increasing response rates, even achieving complete responses in unresectable hepatic metastases [55]. Unfortunately, 
continued treatment with platinum drugs is limited by acute dose-related side effects, e.g. nephrotoxicity, ototoxicity, neurotoxicity, nausea, vomiting, and myelosuppression, and intrinsic or acquired drug resistance [54,55]. Therefore, considerable efforts have been dedicated for developing drug delivery systems that target platinum drugs to solid tumors, for reducing the aforementioned side effects while improving the efficiency of the drugs [56]. Liposomes and polymer-drug conjugates have been the first considered approaches, and several of these systems have reached clinical trials [56]. However, these formulations present recurrent drawbacks, such as loading efficacy, leakage of drugs during storage and in the bloodstream, and in the case of polymer-platinum drug conjugates at high loading ratios, reduction of solubility, crosslinking and aggregation [56]. These increased hydrophobicity and tendency to aggregate of polymer-platinum drug conjugates at high substitution ratios are substantial advantages for assembling polymeric micelles by using block copolymers. In this way, we have prepared polymeric micelles incorporating cisplatin [57] or (trans-l-1,2-diaminocyclohexane)platinum(II) (DACHPt) [58], the parent complex of oxaliplatin, which spontaneously self-assemble in water after the polymer-metal complex formation of the platinum drug with the carboxylate moieties of PEG-b-poly(glutamic acid) copolymer. Both cisplatin- and DACHPt-loaded micelles are being evaluated in clinical trials, and the following are brief summaries of their development.

\subsubsection{Cisplatin-loaded polymeric micelles (NC-6004)}

First polymeric micelles incorporating cisplatin were self-assembled by polymer-metal complex formation between the carboxylic groups of PEG- $b$-poly $(\alpha, \beta$-aspartic acid) and cisplatin in water [59-61]. As the carboxylate-platinum complex can be dissociated by exposing the micelles to chloride ions, these cisplatin-loaded micelles showed a sustained drug release in physiological saline and a slow disassembly of the micelles into unimers $[59,60]$. Following intravenous injection, the micelles showed a 5-fold increase of the plasma AUC, and approximately 4-fold tumor AUC, in contrast to free cisplatin [61]. However, these micelles rapidly decayed in the bloodstream, causing high accumulation in liver and spleen. Therefore, for improving the stability of the micelles in the bloodstream, $2^{\text {nd }}$ generation cisplatin-loaded micelles were prepared from PEG- $b$-poly(L-glutamic acid) (Figure 4) [57]. Compared to the cisplatin-loaded micelles prepared from PEG- $b$-poly $(\alpha, \beta-$ aspartic acid), the micelles from PEG-b-poly(L-glutamic acid) slowly dissociated accompanied with the gradual release of cisplatin via the ligand exchange of $\mathrm{Pt}(\mathrm{II})$ from the carboxylates in poly(Lglutamic acid) to the chloride ions in the medium. These micelles achieved prolonged blood circulation, with 65-fold higher plasma AUC than free cisplatin, resulting in high accumulation in solid tumors (more than 10\% of the injection dose per gram of tumor tissue), while limiting the distribution to kidney, liver and spleen. We have recently demonstrated that the enhanced stability, 
superior blood half-life and tumor selectivity of cisplatin-loaded micelles prepared from PEG- $b$ poly(L-glutamic acid) are associated with the formation of ordered $\alpha$-helical bundles of poly(Lglutamic acid-cisplatin) in the core [62], which stabilize the micelles and promote a gradual erosion-like process in physiological conditions, overcoming their undesirable disintegration during circulation. The high delivery efficiency of the cisplatin-loaded micelles prepared from PEG- $b$ poly(L-glutamic acid) resulted in the improved antitumor efficacy in subcutaneous tumor models of C26 [57], human gastric cancer (MKN-45) [63] and pancreatic adenocarcinoma (BxPC3) [62]. Moreover, the micelles significantly reduced the nephrotoxicity of cisplatin, as the blood urea nitrogen (BUN) levels were unaffected in rats receiving the micelles at $10 \mathrm{mg} \mathrm{kg}^{-1}$ or $15 \mathrm{mg} \mathrm{kg}^{-1}$ in a cisplatin base, whereas free cisplatin at similar dosage induced more than 3-fold increase in BUN [63]. In addition, cisplatin-loaded micelles avoided cisplatin-induced neurotoxicity in rats [63] and ototoxicity in guinea pigs [64], due to the reduced distribution of the micelles to nerve tissue and the organ of Corti, respectively. These outstanding preclinical observations prompted the translation of cisplatin-loaded micelles into clinical studies under the development name NC-6004 (Nanocarrier, Co.).

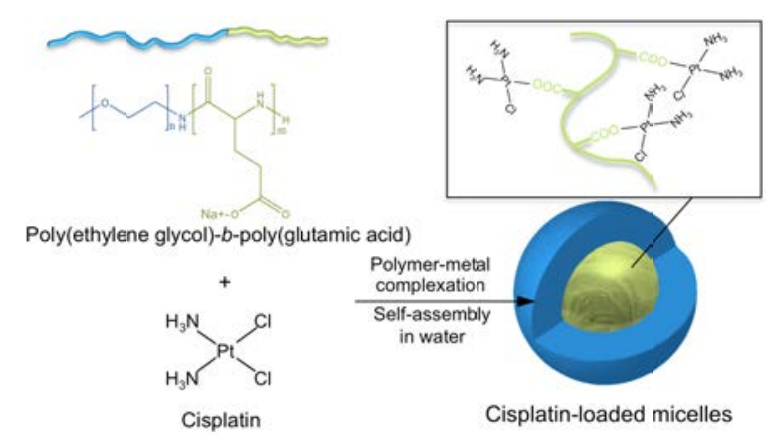

Figure 4. Cisplatin-loaded micelles from PEG- $b$-poly(L-glutamic acid) are self-assembled by the polymer-metal complex formation of cisplatin and the carboxylic groups of poly(L-glutamic acid).

A Phase I clinical trial of NC-6004 was completed in the United Kingdom in 17 patients with advanced solid tumors [65]. NC-6004 was infused once every 3 weeks, starting with a dose of NC-6004 of $10 \mathrm{mg} \mathrm{m}^{-2}$. Although nausea and vomiting are typical adverse effects for cisplatin, those caused by NC-6004 were generally mild. Moreover, NC-6004 did not induced ototoxicity and neurotoxicity, and haematological toxicities were also well tolerated. Moreover, Grade 2 nephrotoxicity was observed at 90 and $120 \mathrm{mg} \mathrm{m}^{-2}$, regardless of the implementation of posthydration and hypersensitivity prophylaxis. However, hypersensitivity reactions caused by NC6004 occurred more frequently than those caused by cisplatin, probably due to the prolonged bioavailability of the micelles, i.e. the $\mathrm{AUC}_{0 \text {-inf }}$ of $\mathrm{NC}-6004$ was more than 60 -fold higher than that of cisplatin (Table 2). Therefore, patients receiving NC-6004 are to be pretreated with antiallergic 
medication. From this study, the MTD was concluded to be $120 \mathrm{mg} \mathrm{m}^{-2}$ due to nephrotoxicity events and the recommended dose for Phase II studies was $90 \mathrm{mg} \mathrm{m}^{-2}$ (Table 2). In addition, 2 patients with pancreatic cancer demonstrated the stable disease.

A Phase I/II study of NC-6004 in combination with gemcitabine in patients with pancreatic cancer was also conducted in Taiwan and Singapore [66]. The objectives of the study were to determine the MTD and recommended dose of NC-6004 in combination with gemcitabine in the treatment of pancreatic cancer. Nineteen-patients with pancreatic cancer were treated with NC-6004 at a dose of 30,60, 90 and $120 \mathrm{mg} \mathrm{m}^{-2}$ once every 3 weeks, and gemcitabine at $1000 \mathrm{mg} \mathrm{m}^{-2}$ twice every 3 weeks on days 1 and 8 . Steroid regimen was implemented to reduce hypersensitivity to NC6004 observed in previous Phase I study. Dose limiting toxicities were observed at $120 \mathrm{mg} \mathrm{m}^{-2}$, indicating that the MTD of NC-6004 in combination with gemcitabine was similar to NC-6004 monotherapy. The recommended dose was also $90 \mathrm{mg} \mathrm{m}^{-2}$, which is the same dose for NC-6004 monotherapy. Efficacy evaluation demonstrated a disease control ratio of $64.7 \%$, accounting for 1 partial response and 10 stable diseases. These Phase II results denoted the good tolerability and acceptable efficacy of NC-6004 in combination with gemcitabine in patients with pancreatic cancer. NC-6004 has recently proceeded into Phase III studies for determining their efficacy in combination with gemcitabine versus gemcitabine alone in patients with locally advanced or metastatic pancreatic cancer (NCT02043288).

\subsection{2 (trans-l-1,2-diaminocyclohexane)platinum(II) (DACHPt)-loaded micelles (NC-4016)}

Based on the promising results of cisplatin-loaded micelles prepared from PEG- $b$-poly(Lglutamic acid), polymeric micelles incorporating DACHPt were prepared for enhancing the delivery of the parent complex of oxaliplatin to solid tumors, while reducing the toxicities associated with oxaliplatin treatment [58]. Due to the high stability of DACHPt-loaded micelles in physiological conditions, the micelles significantly extended the blood circulation of the platinum drug after bolus injection, achieving more than 1000-fold plasma $\mathrm{AUC}_{0-72 \mathrm{~h}}$ compared to oxaliplatin, and improved the accumulation of the platinum drug in tumor tissues based on the EPR effect [67]. The $\mathrm{AUC}_{0-72 \mathrm{~h}}$ for DACHPt-loaded micelles in subcutaneous $\mathrm{C} 26$ tumors was approximately 17-fold higher than that of free oxaliplatin. Moreover, by using dual-fluorescent labeled DACHPt-loaded micelles, which can report their position and kinetic stability by following the fluorescence of a dye installed on the PEG-shell and the fluorescence dequenching of a core-conjugated dye, respectively, and following the in vivo fate of these micelles by intravital confocal laser scanning microscopy, we observed that DACHPt-loaded micelles maintained their micelle form during blood circulation, extravasated from blood vessels into tumor tissues and dissociated inside the cells within tumors, enhancing the delivery of the platinum drugs to the nucleus of cells [9]. Thus, besides the high 
tumor accumulation of DACHPt-loaded micelles, their subcellular drug targeting is a significant benefit for augmenting the efficiency of platinum drugs, and avoiding detoxification mechanisms in the cytoplasm. Because of this improved intracellular delivery, as well as their enhanced accumulation in tumor tissues, DACHPt-loaded micelles were able to overcome oxaliplatinresistance in a model of human colon cancer, achieving strong suppression of the tumor growth [9]. Moreover, DACHPt-loaded micelles demonstrated higher efficacy than oxaliplatin in various tumor models, including murine colon carcinoma [67], human pancreatic [8] and scirrhous gastric cancer [68], melanoma[69], as well as strong antimetastatic effect against intraperitoneal HeLa metastases, lymph node metastatases of gastric cancer [68] and lung metastases of melanoma [69]. Moreover, the weekly injection of DACHPt-loaded micelles at $2 \mathrm{mg} \mathrm{kg}^{-1}$ for over 8 weeks in transgenic mice developing spontaneous pancreatic tumors effectively suppressed the tumor growth and extended the survival of mice, without any evident toxicity [70], suggesting the utility of these micelles for repeated chemotherapy cycles. Moreover, because the repeated administration of oxaliplatin causes severe peripheral neurotoxicities, which aggravate with the cumulative dosage, leading in many cases to therapy withdrawal, the mechanical allodynia after 9 administrations of oxaliplatin and micelles was evaluated in mice to determine their neurotoxicity [71]. While oxaliplatin-treated mice were significantly more sensitive to the mechanical stimuli, mice receiving DACHPt-loaded micelles and control mice showed comparable responses, demonstrating the reduced neurotoxicity of the micelles [71], which is a significant advantage for avoiding oxaliplatin-related toxicities in the clinical stage. Supported by these preclinical results, DACHPt-loaded micelles proceeded into clinical studies under the development name NC-4016 (Nanocarrier, Co.).

A Phase I clinical trial of NC-4016 has started in November 2013 at The University of Texas MD Anderson Cancer Center in the US to find the MTD, dose limiting toxicities and recommended dosage of NC-4016 in patients with advanced solid tumors or lymphoma. In this trial, NC-4016 is being administered in $2 \mathrm{~h}$ intravenous infusion once every 3 weeks, with an initial dose of $15 \mathrm{mg} \mathrm{m}^{-2}$ (NCT01999491).

\section{Recent innovations on polymeric micelles}

As highlighted in previous sections, the properties of polymeric micelles can be readily adjusted by precisely engineering the constituent block copolymers for improving drug loading, release rate, pharmacokinetics and tumor targeting ability. In this way, the end-group of the PEG segment can be readily modified with ligands capable of recognition of cell-specific surface receptors, providing cellular selectivity and superior intracellular delivery to polymeric micelles. The effect of various ligands [72], including antibodies[73] and antibody fragments[74], aptamers [75], peptides [76,77] and small molecules [69,78], installed on nanocarriers has been confirmed to 
improve their targeting efficiency. The efficiency of these ligand-installed carriers depends on design aspects, such as the density of ligands on the surface of nanocarriers, as well as the characteristics of the selected ligand-receptor system, including the binding affinities, which may be enhanced due to the multivalent effect of several ligands on the carriers, the receptor internalization, the biodistribution and availability of the receptors, and the variable expression of the receptors with tumor stage [72]. In this sense, Arg-Gly-Asp (RGD) peptides have been recognized as specific ligands for targeting $\alpha v \beta 3$ and $\alpha v \beta 5$ integrins overexpressed in neovasculature and cancer cells [79]. However, because of the relatively low affinity in the nanomolar range of linear RGD peptides and their rapid degradation in biological environments, cyclic-RGD (cRGD) peptides were developed for enhancing both selectivity to $\alpha v \beta 3$ and $\alpha v \beta 5$ integrins and stability compared to linear RGD peptides $[80,81]$. We have recently demonstrated that DACHPt-loaded polymeric micelles having cRGD peptides on their surface not only enhanced the cellular uptake of micelles by cancer cells, but also achieved efficient drug delivery in a mouse model of glioblastoma [77]. Even though glioblastoma is notorious for its poor permeability due to the presence of the blood-brain tumor barrier [82], these cRGD-installed micelles rapidly penetrated and accumulated within tumor tissues, while micelles modified with a non-targeting ligand, i.e. cyclic-Arg-Ala-Asp (cRAD), showed significantly lower extravasation and accumulation within same tumors, suggesting an active extravasation pathway for cRGD-installed micelles, most likely transcytosis [77]. Thus, besides the enhanced binding and internalization by target cells, ligands can also be used for overcoming several biological barriers, including extravasation and tissue penetration in, otherwise, impermeable tissues.

Polymeric micelles also offer high versatility for incorporating a broad range of bioactive molecules by engineering the core forming segments of the block copolymers. From our former observations on the self-assembly of polymeric micelles through electrostatic interaction by pairing oppositely-charged block copolymers [83,84], we have developed several polymeric micelles, so called polyion complex (PIC) micelles (Figure 1), incorporating charged macromolecules, such as antisense oligonucleotides [84], plasmid DNA [85], proteins [86] small interfering ribonucleic acid (siRNA) [87], messenger RNA (mRNA) [88] and negatively charged photosensitizers [89]. The ion pairing of these biomolecules with PEG-b-polycation copolymers allows stable assembly because of counter ion releasing to get entropy gain as well as of substantial lowering of dielectric constant in the microenvironment of the core. Moreover, the PEG shielding of PIC micelles reduces the dissociation of the complexes in biological environments by avoiding polyion exchange with charged biomacromolecules, including serum albumin in blood and heparan sulfate in tissues, while protect the aggregation of the polyplexes in the core with plasma proteins and plateletes [90]. PIC micelles can be further stabilized by reversible covalent crosslinking of their core, e.g. disulfide 
bonds [91], which can be cleaved at intracellular conditions, and by the addition of hydrophobic groups, such as cholesterol [92], to the core-forming segment, which augment the endurance of PIC micelles to the harsh in vivo conditions, extending their half-life in the bloodstream and allowing the delivery of intact biomolecules to the therapeutic targets. Because these targets are generally located in intracellular compartments, PIC micelles should also be able to escape from endosomal compartments after endocytosis for avoiding the degradation of their payload in lysosomes, while delivering the biomolecules to the subcellular destinations [93]. Accordingly, the core-forming polycations can be modified with endosomal escape functions, which can control the buffering capacity and the amount of cationic charges, allowing the interaction of the PIC micelles with endosomal membranes [93]. Thus, by using polycations having amines with low pKa, the polycations can protonate at endosomal $\mathrm{pH}$ inducing strong buffering effect and increasing the density of positive charges. We have recently engineered the endosomal escape of polyplexes by preparing a library of polyaspartamides via aminolysis of poly( $\beta$-benzyl-L-aspartate) [94], and found that polycations having even aminoethylene units, such as poly $\{\mathrm{N}-[\mathrm{N}-(2$-aminoethyl)-2aminoethyl $]$ aspartamide $\} \quad[\mathrm{P}(\mathrm{Asp}(\mathrm{DET})]$ and poly[N-(N- $\{\mathrm{N}-[\mathrm{N}-(2$-aminoethyl)-2-aminoethyl $]-2-$ aminoethyl $\}$-2-aminoethyl)aspartamide] [P(Asp(TEP)], can shift from monoprotonation of their diaminoethane groups at extracellular $(\mathrm{pH}$ 7.4) to biprotonation at endosomal $\mathrm{pH}$ (5.5), enhancing the in vitro endosomal escape efficiency with low cytotoxicity [95,96]. Moreover, these polyaspartamides can degrade faster than natural cationic poly(amino acid)s, eliminating the risk of cytotoxicity from prolonged exposure to polycations [97]. PIC micelles prepared from block copolymers having these polyaspartamides have safely enhanced the delivery of biomacromolecules the cytosol of cells and the gene transfection in vitro and in vivo [88, $92,93,95,96,98]$.

These features of PIC micelles have been demonstrated of great utility for RNA interference therapies, as systemically injected free siRNA is rapidly degraded by enzymes and cleared from circulation by kidneys, while it cannot reach its intracelullar therapeutic targets due to low cellular uptake and degradation in lysosomes. To reduce the interference on the electrostatic interactions between the siRNA and the polycation segment in the core of PIC micelles by charged biomacromolecules in biological environments, additional stabilization of siRNA-loaded PIC micelles facilitates the successful siRNA delivery in vivo. For siRNA delivery to tumors, siRNAloaded PIC micelles have been constructed from PEG-b-poly(L-lysine) copolymers containing iminothiolane groups for crosslinking the micelle structure via disulfide bonds in the core $[99,100]$. Moreover, cRGD peptide was also installed on the PEG-shell of the micelles for improving the tumor targeting as well as biological activity. These micelles showed good gene silencing ability, improved cellular internalization, and broad subcellular distribution due to their enhanced stability 
and cRGD-mediated delivery [99]. After intravenous injection, these micelles achieved high accumulation in tumor tissues as well as tumor vasculature and, by delivering antiangiogenic siRNA, these micelles elicited significant inhibition of the growth rate of subcutaneous HeLa tumor models [100]. In addition, siRNA-loaded PIC micelles with endosomal escape ability were prepared from PEG- $b$-P(Asp(TEP)) copolymers [101]. These micelles were stabilized by conjugating hydrophobic cholesteryl groups to the side groups of $\mathrm{P}(\mathrm{Asp}(\mathrm{TEP})$ ) segment, extending the circulation of the micelles in the bloodstream [101]. Moreover, by installing cRGD on the surface of these cholesterol-stabilized siRNA-loaded micelles, we achieved improved delivery of polo-like kinase 1 (Plk1) siRNA in a subcutaneous model of human lung cancer (A549) and attained significant antitumor efficacy by sequence-specific gene silencing in tumor tissues. Besides hydrophobic cholesterol, steaoryl moieties have also been used for stabilizing the structure of siRNA-loaded micelles from PEG-SS-P(Asp(DET)) copolymers [102]. Because the disulfide bond between PEG and P(Asp(DET)) can be cleaved under reductive conditions of tumor tissues and cytoplasm, these micelles can selectively detach their PEG-shell and augment transfection efficiency. Thus, while the hydrophobic stearoyl molecules in the core increase the resilience of the siRNA-loaded micelles in blood, these smart micelles accomplished significant gene silencing of vascular endothelial growth factor (VEGF) in a mouse model of pancreatic tumor, reducing the growth rate of tumors. Furthermore, as siRNA-based therapies have the potential for treating a wide range of diseases, we have recently extended the use of siRNA-loaded micelles from PEG- $b$ poly(L-lysine) for treating glomerulonephritis in a mouse model [103]. The relatively small diameter of these micelles $(10-20 \mathrm{~nm})$ allowed them to access to the mesangium of kidneys and deliver mitogen-activated protein kinase 1 (MAPK1) siRNA, suppressing glomerular MAPK1 mRNA and improving kidney function.

siRNA has also been incorporated in calcium phosphate (CaP)-based polymeric micelles for improving its stability in biological environments and enhacing its bioavailability. CaP has been widely used as a biomaterial because it is safe, biocompatible and inexpensive, and based on the high affinity of $\mathrm{CaP}$ for nucleic acids, $\mathrm{CaP}$ nanoparticles have been developed for improving the stability of these biomolecules in biological environments, increasing their cellular uptake and enhancing the transfection ability (Figure 1) [104-109]. By using PEG-b-polyanion copolymers, we have prepared CaP hybrid micelles with narrowly distributed diameter [104-110], where the polyanion segment facilitates both the growth of $\mathrm{CaP}$ nanoparticle and the binding $\mathrm{CaP}$ with the polymer chains, while the PEG block forms a nonionic and hydrophilic shell, enhancing the colloidal stability. Former CaP-based siRNA-loaded micelles were prepared by mixing siRNA with PEG-b-poly $(\alpha, \beta$-aspartic acid) [105] or PEG- $b$-poly(methacrylic acid) [106] copolymers, showing excellent colloidal stability and high loading capacity (approximately $80 \%$ of siRNA feed). We 
have also used siRNA as the CaP-interacting polyanion segment in PEG-SS-siRNA copolymers and showed the formation of siRNA-loaded CaP-based micelles, which can detach their PEG shell under reductive conditions [107]. Even though these micelles do not have buffering polycations for endosomal escape, they achieved effective knockdown of luciferase genes in the hepatocarcinoma Huh-7 cells, probably by disrupting endosomal membranes through increased osmotic pressure in endosomes due to the dissolution of $\mathrm{CaP}$ in acidic conditions. By introducing polycations with endosomal escape ability, the delivery efficiency of siRNA-loaded CaP-based micelles can be further enhanced. However, because polycations cannot stably associate with $\mathrm{CaP}$, we have capped the amine moieties of PEG- $b-\mathrm{P}(\mathrm{Asp}(\mathrm{DET}))$ copolymer with a $\mathrm{pH}-$ responsive anionic group, that is, cis-aconitic amide (Figure 5A and B), which can be removed at endosomal $\mathrm{pH}$, recovering the endosomal escape potency (Figure 5C) $[108,109]$. These CaP-based micelles were demonstrated to safely deliver siRNA to tumor tissues in a spontaneous bioluminescent pancreatic cancer model in transgenic mice, significantly reducing the luciferase signal (Figure 5D and E), without any toxicity [109]. Moreover, by delivering VEGF-siRNA, these micelles achieved significant antitumor activity, eliciting approximately $68 \%$ of VEGF gene silencing in subcutaneous human pancreatic tumors [108]. These results indicate CaP-base micelle systems as promising formulation toward siRNA-based cancer therapies.

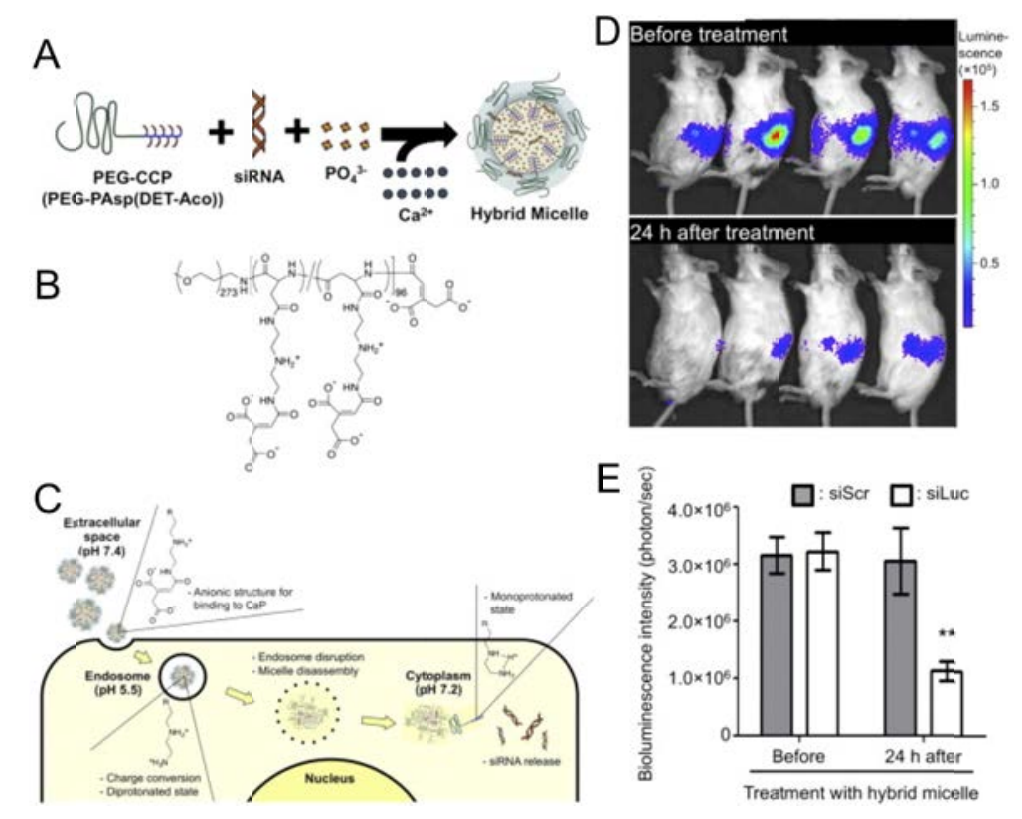

Figure 5. A. Scheme of the preparation of CaP-based siRNA-loaded micelles prepared from PEG- $b$-P(Asp(DET)) copolymer having a pH-responsive anionic group, i.e. cis-aconitic amide, capping the amine moieties. B. Chemical structure of PEG- $b-\mathrm{P}(\mathrm{Asp}(\mathrm{DET}))$ copolymer bearing cisaconitic amide groups. C. Intracellular pathway of these CaP-based siRNA-loaded micelles. After the micelles are internalized by endocytosis, the cis-aconitic amide groups are removed from PEG$b-\mathrm{P}(\mathrm{Asp}(\mathrm{DET}))$ at endosomal $\mathrm{pH}(\mathrm{pH} 5.5)$, recovering the amine moieties, which can disrupt the 
endosomal membranes and release the siRNA to the cytosol. D. In vivo luciferase-silencing activity in the spontaneous bioluminescent pancreatic tumors from transgenic mice $24 \mathrm{~h}$ after systemic administration of micelles containing siLuc (20 $\mu \mathrm{g}$ siRNA/mouse). E. Bioluminescent signal in the pancreatic tumors after intravenous injection of micelles containing either siLuc or siScr $(20 \mu \mathrm{g}$ siRNA/mouse). Results are expressed as mean plus S.D. $(n=16)$. Statistical analysis performed by ANOVA followed by Newman-Keuls $(* \mathrm{P}<0.05 ; * * \mathrm{P}<0.01)$. Reprinted with permission from reference [109].

Beyond siRNA and nucleic acids, CaP-based micelles can incorporate a wide range of negatively charged molecules. Accordingly, we have recently incorporated diethylenetriaminepentaacetic acid gadolinium (III) (Gd-DTPA), a clinically used T1-weighed magnetic resonance imaging (MRI) constrast agent, for preparing CaP-based micelles for imaging and diagnosis of solid tumors [110]. While free Gd-DTPA was not capable of MRI contrast enhancement of tumors, these micelles significantly augmented the signal in cancerous tissues due to their high accumulation in tumor positions, as well as the increase of the relaxivity of Gd-DTPA within the micelles compared to free Gd-DTPA. Moreover, because Gd-DTPA is released from these CaP-based micelles, the toxicity issues associated with the prolonged exposure of Gd-DTPA in the body can be avoided due to the kidney clearance of released Gd-DTPA. These results indicate the high potential of Gd-DTPA-loaded CaP-based micelles as safe and effective contrast agents for noninvasive cancer diagnosis.

The incorporation of imaging or reporter molecules into the structure of polymeric micelles is a useful strategy for validating their design and biological performance. Moreover, combining reporter and therapeutic molecules within the same platform allows for simultaneous diagnosis and therapy, so called theranostics, which is an attractive strategy for real-time in-situ evaluation of pharmacokinetics, pharmacodynamics, therapeutic responses in individual patients [111]. We have found this approach feasible by combining DACHPt-loaded micelles with Gd-DTPA, and following their accumulation and their significant therapeutic activity in orthotopic pancreatic tumors by MRI [112]. Theranostic platforms have the potential to provide safe and efficient management of disease and therapies, and their clinical translation will largely depend on their ability to optimize doses, toxicities, clearance rates, and imaging and therapeutic efficiencies.

\section{Future prospects}

The positive clinical results of anticancer drug-loaded polymeric micelles with efficacy enhancements and reduction of side effects, which indicate not only the improvement of prognosis but also the quality of life of patients, and the recent progress of NK105 and NC-6004 into Phase III 
studies, allow envisioning the imminent translation of polymeric micelles into the clinic. Further application of drug-loaded polymeric micelles in combination with other therapeutic agents is already being considered, as cancer cells may circumvent cytotoxic effects of monotherapy. Accordingly, current clinical studies comprising the combination of NK012 combined with 5FU/LV or carboplatin, and NC-6004 with gemcitabine may provide unprecedented efficacies. Moreover, emergent combination therapies with various polymeric micelles may also achieve exceptional synergy with reduced side effects, as recently demonstrated by the combination of NC4016 and NC-6300 [71], which was significantly more effective and safe than the combination of oxaliplatin and Epi in a model of human gastric cancer. Moreover, as polymeric micelles can incorporate multiple drugs at therapeutic concentrations, multidrug-loaded micelles may facilitate optimization of pharmacokinetics, even at the cellular level, and achieve synchronized and cooperative drug action. Even though novel regulations and evaluation guidelines may be necessary for proceeding multidrug-loaded micelles into human studies, such micelles have the potential to elicit outstanding therapeutic effects by rationally combining therapies at the molecular level within cancer cells.

Further applications of polymeric micelles in tissues other than cancer, where the vascular permeability is limited, can be achieved by systemically supplying micelles with the capacity to overcome biological barriers, including extravasation, tissue penetration, and cellular internalization at the target site. Ligand-installed polymeric micelles have the potential for overcoming such biological barriers by taking advantage of receptor-mediated transport mechanisms. As a wide range of bioactive molecules can be stably encapsulated in the core of micelles, safe and efficient diagnostic and therapeutic strategies can be envisaged through the development of sophisticated polymeric micelles, evolving into self-sufficient nanomachines for the management of a wide-range of medical diseases or conditions.

\section{Acknowledgments}

This work was supported by Funding Program for World-Leading Innovative R\&D on Science and Technology (FIRST Program) from Japan Society for the Promotion of Science (JSPS), Center of Innovation (COI) Program from Japan Science and Technology Agency (JST), and Takeda Science Foundation. H.C. would like to thank Mr. Shigeto Fukushima for valuable discussions on NK911.

\section{References}

1. J. Ferlay, I. Soerjomataram, M. Ervik, R. Dikshit, S. Eser, C. Mathers, M. Rebelo, DM. Parkin, D. Forman, Bray, F. GLOBOCAN 2012 v1.0, Cancer Incidence and Mortality Worldwide: IARC CancerBase No. 11 (World Hearth Organization) 
2. R. Duncan, The dawning era of polymer therapeutics, Nat. Rev. Drug Discov. 2 (2003) 347360.

3. M.E. Davis, Z. Chen, D. Shin, Nanoparticle therapeutics: an emerging treatment modality for cancer, Nat. Rev. Drug Discov. 7 (2008) 771-782.

4. K. Kataoka, A. Harada, Y. Nagasaki, Block copolymer micelles for drug delivery: design, characterization and biological significance, Adv. Drug Deliv. Rev. 47 (2001) 113-131.

5. Y. Matsumura, H. Maeda, A new concept for macromolecular therapeutics in cancer chemotherapy: mechanism of tumoritropic accumulation of proteins and the antitumor agent smancs, Cancer Res. 46 (1986) 6387-6392.

6. N. Nishiyama, K. Kataoka, Current state, achievements, and future prospects of polymeric micelles as nanocarriers for drug and gene delivery, Pharmacol. Ther. 112 (2006) 630-648.

7. S.T. Reddy, A.J. van der Vlies, E. Simeoni, V. Angeli, G.J. Randolph, C.P. O'Neil, L.K. Lee, M.A. Swartz, J.A. Hubbell, Exploiting lymphatic transport and complement activation in nanoparticle vaccines, Nat. Biotechnol. 25 (2007) 1159-1164.

8. H. Cabral, Y. Matsumoto, K. Mizuno, Q. Chen, M. Murakami, M. Kimura, Y. Terada, M.R. Kano, K. Miyazono, M. Uesaka, N. Nishiyama, K. Kataoka, Accumulation of sub-100 nm polymeric micelles in poorly permeable tumours depends on size, Nat. Nanotechnol. 6 (2011) 815-822.

9. M. Murakami, H. Cabral, Y. Matsumoto, S. Wu, M.R. Kano, T. Yamori, N. Nishiyama, K. Kataoka, Improving drug potency and efficacy by nanocarrier-mediated subcellular targeting, Sci. Transl. Med. 3 (2011) 64ra2.

10. Y. Matsumura, T. Hamaguchi, T. Ura, K. Muro, Y. Yamada, Y. Shimada, K. Shirao, T. Okusaka, Phase I clinical trial and pharmacokinetic evaluation of NK911, a micelleencapsulated doxorubicin, Br. J. Cancer 91 (2004) 1775-1781.

11. Y. Matsumura, K. Kataoka, Preclinical and clinical studies of anticancer agent-incorporating polymer micelles, Cancer Sci. 100 (2009) 572-579.

12. E. Saltiel, W. McGuire, Doxorubicin (Adriamycin) Cardiomyopathy-A Critical Review, West. J. Med. 139 (1983) 332-341.

13. R. Duncan, H.C. Cable, J.B. Lloyd, P. Rejmanova, J. Kopeček, Polymers containing enzymatically degradable bonds. 7. Design of oligopeptide side-chains in poly[n-(2hydroxypropyl)methacrylamide] copolymers to promote efficient degradation by lysosomalenzymes, Makromol. Chem. Macromol. Chem. Phys. 184 (1983) 1997-2008.

14. P.A. Vasey, S.B. Kaye, R. Morrison, C. Twelves, P. Wilson, R. Duncan, A.H. Thomson, L.S. Murray, T.E. Hilditch, T. Murray, S. Burtles, D. Fraier, E. Frigerio, J. Cassidy, Phase I clinical and pharmacokinetic study of PK1 [N-(2-hydroxypropyl)methacrylamide copolymer doxorubicin]: first member of a new class of chemotherapeutic agents-drug-polymer conjugates, Clin. Cancer Res. 5 (1999) 83-94.

15. S.E. Krown, D.W. Northfelt, D. Osoba, J.S. Stewart, Use of liposomal anthracyclines in Kaposi's sarcoma, Semin Oncol. 31(2004) 36-52.

16. P.G. Rose, Pegylated liposomal doxorubicin: optimizing the dosing schedule in ovarian cancer, Oncologist 10 (2005) 205-214.

17. A.T. Perez, G.H. Domenech, C. Frankel, C.L. Vogel, Pegylated Liposomal Doxorubicin (Doxil®) for Metastatic Breast Cancer: The Cancer Research Network, Inc., Experience, Cancer Invest. 20 (2002) 22-29.

18. M. Yokoyama, S. Inoue, K. Kataoka, N. Yui, T. Okano, Y. Sakurai, Molecular design for missile drug: synthesis of adriamycin conjugated with immunoglobulin $G$ using poly(ethylene glycol)-block-poly(aspartic acid) as intermediate carrier, Makromol. Chem. 190 (1989) 2041-2054.

19. M. Yokoyama, M. Miyauchi, N. Yamada, T. Okano, Y. Sakurai, I. Shohei, K. Kataoka, Polymeric micelles as novel drug carrier: Adriamycin-conjugated poly(ethylene glycol)poly(aspartic acid) block copolymer, J. Control Release 11 (1990) 269-278. 
20. M. Menozzi, L. Valentini, E. Vannini, F. Arcamone, Self-association of doxorubicin and related compounds in aqueous solution, J Pharm Sci. 73 (1984) 766-70.

21. S. Fukushima, M. Machida, T. Akutsu, K. Shimizu, S. Tanaka, K. Okamoto, H. Mashiba, M. Yokoyama, T. Okano, Y. Sakurai, K. Kataoka, Roles of adriamycin and adriamycin dimer in antitumor activity of the polymeric micelle carrier system, Colloids and Surfaces B: Biointerfaces, 16 (1999) 227-236.

22. T. Nakanishi, S. Fukushima, K. Okamoto, M. Suzuki, Y. Matsumura, M. Yokoyama, T. Okano, Y. Sakurai, K. Kataoka, Development of the polymer micelle carrier system for doxorubicin, J. Control. Release 74 (2001) 295-302.

23. Y. Zhao, D.Y. Alakhova, J.O. Kim, T.K. Bronich, A.V. Kabanov, A simple way to enhance Doxil ${ }^{\circledR}$ therapy: Drug release from liposomes at the tumor site by amphiphilic block copolymer, J. Control. Release 168 (2013) 61-69.

24. E.K. Rowinsky, R.C. Donehower, Paclitaxel (Taxol), N. Engl. J. Med. 332 (1995) 10041014.

25. Z. Zhang, L. Mei, S.S. Feng, Paclitaxel drug delivery systems, Expert Opin. Drug Deliv. 10 (2013) 325-340.

26. M.R. Green, G.M. Manikhas, S. Orlov, B. Afanasyev, A. M. Makhson, P. Bhar, M. J. Hawkins, Abraxane ${ }^{\circledR}$, a novel Cremophor ${ }^{\circledR}$-free, albumin-bound particle form of paclitaxel for the treatment of advanced non-small-cell lung cancer, Ann. Oncol. 17 (2006) 1263-1268.

27. E. Miele, G. P. Spinelli, E. Miele, F. Tomao, S. Tomao, Albumin-bound formulation of paclitaxel (Abraxane ${ }^{\circledR}$ ABI-007) in the treatment of breast cancer, Int. J. Nanomedicine. 4 (2009) 99-105.

28. J.W. Singer, Paclitaxel poliglumex (XYOTAX, CT-2103): a macromolecular taxane, J Control. Release 109 (2005) 120-126.

29. K.S. Lee, H.C. Chung, S.A. Im, Y.H. Park, C.S. Kim, S.B. Kim, S.Y. Rha, M.Y. Lee, J. Ro, Multicenter phase II trial of Genexol-PM, a Cremophor-free, polymeric micelle formulation of paclitaxel, in patients with metastatic breast cancer, Breast Cancer Res. Treat. 108 (2008) 241-250.

30. S. Cammas, T. Matsumoto, T. Okano, Y. Sakurai, K. Kataoka, Design of functional polymeric micelles as site-specific drug vehicles based on poly $(\alpha$-hydroxy ethylene oxideco- $\beta$-benzyl L-aspartate) block copolymers, Mater. Sci. Eng., C 4 (1997) 241-247.

31. K. Kataoka, T. Matsumoto, M. Yokoyama, T. Okano, Y. Sakurai, S. Fukushima, K. Okamoto, G. S. Kwon, Doxorubicin-loaded poly(ethylene glycol)-poly( $\beta$-benzyl-1aspartate) copolymer micelles: their pharmaceutical characteristics and biological significance, J. Control. Release 64 (2000) 143-153.

32. T. Hamaguchi, Y. Matsumura, M. Suzuki, K. Shimizu, R. Goda, I. Nakamura, I. Nakatomi, M. Yokoyama, K. Kataoka, T. Kakizoe, NK105, a paclitaxel-incorporating micellar nanoparticle formulation, can extend in vivo antitumour activity and reduce the neurotoxicity of paclitaxel, Br. J. Cancer. 92 (2005) 1240-1246.

33. T. Hamaguchi, K. Kato, H. Yasui, C. Morizane, M. Ikeda, H. Ueno, K. Muro, Y. Yamada, T. Okusaka, K. Shirao, Y. Shimada, H. Nakahama, Y. Matsumura, A phase I and pharmacokinetic study of NK105, a paclitaxel-incorporating micellar nanoparticle formulation, Br. J. Cancer 97 (2007) 170-176.

34. K. Kato, K. Chin, T. Yoshikawa, K. Yamaguchi, Y. Tsuji, T. Esaki, K. Sakai, M. Kimura, T. Hamaguchi, Y. Shimada, Y. Matsumura, R.I. Ikeda, Phase II study of NK105, a paclitaxelincorporating micellar nanoparticle, for previously treated advanced or recurrent gastric cancer, Invest .New Drugs 30 (2012) 1621-1627.

35. Y. Kawato, M. Aonuma, Y. Hirota, H. Kuga, K. Sato, Intracellular roles of SN-38, a metabolite of the camptothecin derivative CPT-11, in the antitumor effect of CPT-11, Cancer Res. 51 (1991) 4187-4191. 
36. F. Koizumi, M. Kitagawa, T. Negishi, T. Onda, S. Matsumoto, T. Hamaguchi, Y. Matsumura, Novel SN-38-incorporating polymeric micelles, NK012, eradicate vascular endothelial growth factor-secreting bulky tumors, Cancer Res. 66 (2006) 10048-10056.

37. Y. Xiao, M. Cushman, Effect of E-ring modifications in camptothecin on topoisomerase I inhibition: a quantum mechanics treatment, J. Org. Chem. 70 (2005) 9584-9587.

38. J. Kuroda, J. Kuratsu, M. Yasunaga, Y. Koga, Y. Saito, Y. Matsumura. Potent antitumor effect of SN-38-incorporating polymeric micelle, NK012, against malignant glioma, Int J Cancer. 124 (2009) 2505-2511.

39. M. Sumitomo, F. Koizumi, T. Asano, A. Horiguchi, K. Ito, T. Asano, T. Kakizoe, M. Hayakawa, Y. Matsumura, Novel SN-38-incorporated polymeric micelle, NK012, strongly suppresses renal cancer progression, Cancer Res. 68 (2008) 1631-1635.

40. T.E. Nakajima, K. Yanagihara, M. Takigahira, M. Yasunaga, K. Kato, T. Hamaguchi, Y. Yamada, Y. Shimada, K. Mihara, T. Ochiya, Y. Matsumura, Antitumor effect of SN-38releasing polymeric micelles, NK012, on spontaneous peritoneal metastases from orthotopic gastric cancer in mice compared with irinotecan, Cancer Res. 68 (2008) 9318-9322.

41. Y. Saito, M. Yasunaga, J. Kuroda, Y. Koga, Y. Matsumura, Enhanced distribution of NK012, a polymeric micelle-encapsulated SN-38, and sustained release of SN-38 within tumors can beat a hypovascular tumor, Cancer Sci. 99 (2008) 1258-1264

42. Y. Saito, M. Yasunaga, J. Kuroda, Y. Koga, Y. Matsumura, Antitumour activity of NK012, SN-38-incorporating polymeric micelles, in hypovascular orthotopic pancreatic tumour, Eur. J Cancer. 46 (2010) 650-658.

43. T.E. Nakajima, M. Yasunaga, Y. Kano, F. Koizumi, K. Kato, T. Hamaguchi, Y. Yamada, K. Shirao, Y. Shimada, Y. Matsumura, Synergistic antitumor activity of the novel SN-38incorporating polymeric micelles, NK012, combined with 5-fluorouracil in a mouse model of colorectal cancer, as compared with that of irinotecan plus 5-fluorouracil, Int. J. Cancer 122 (2008) 2148-2153.

44. T. Nagano, M. Yasunaga, K. Goto, H. Kenmotsu, Y. Koga, J. Kuroda, Y. Nishimura, T. Sugino, Y. Nishiwaki, Y. Matsumura, Antitumor activity of NK012 combined with cisplatin against small cell lung cancer and intestinal mucosal changes in tumor-bearing mouse after treatment, Clin. Cancer Res. 15 (2009) 4348-4355.

45. T. Hamaguchi, T. Doi, T. Eguchi-Nakajima, K. Kato K, Y. Yamada, Y. Shimada, N. Fuse, A. Ohtsu, S. Matsumoto, M. Takanashi, Y. Matsumura, Phase I study of NK012, a novel SN-38-incorporating micellar nanoparticle, in adult patients with solid tumors, Clin. Cancer Res. 16 (2010) 5058-5066.

46. S. Fields Jones, H.A. Burris, J.R. Infante, F.A. Greco, D.R. Spigel, S. Kawamura, T. Ishioka, H. Yamazaki, J.C. Bendell, A phase I study of NK012 in combination with 5-fluorouracil with or without leucovorin in patients (pts) with advanced solid tumors, J. Clin Oncol 30 (2012) abstr e13076.

47. D. Abigerges, G. Chabot, J. Armand, P. Herait, A. Gouyette, D. Gandia, Phase I and pharmacologic studies of the camptothecin analog irinotecan administered every 3 weeks in cancer patients, J. Clin. Oncol. 13 (1995) 210-221.

48. E. Raefsky, D. R. Spigel, J. R. Infante, J. C. Bendell, S. F. Jones, A. J. Lipman, D. Trent, S. Kawamura, F. A. Greco, J. D. Hainsworth and H. A. Burris, Phase II study of NK012 in relapsed small cell lung cancer. J. Clin. Oncol. 2011 ASCO Annual Meeting Abstracts 29 (2011) 7079.

49. C.C. Cain, D.M. Sipe, R.F. Murphy, Regulation of endocytic $\mathrm{pH}$ by the $\mathrm{Na}+, \mathrm{K}+-\mathrm{ATPase}$ in living cells, Proc Natl Acad Sci U S A. 86 (1989) 544-548.

50. Y. Bae, S. Fukushima, A. Harada, K. Kataoka, Design of Environment-Sensitive Supramolecular Assemblies for Intracellular Drug Delivery: Polymeric Micelles that are Responsive to Intracellular pH Change, Angew. Chem. Int. Ed., 42 (2003) 4640-4643.

51. Y. Bae, N. Nishiyama, S. Fukushima, H. Koyama, M. Yasuhiro, K. Kataoka, Preparation and biological characterization of polymeric micelle drug carriers with intracellular $\mathrm{pH}-$ 
triggered drug release property: tumor permeability, controlled subcellular drug distribution, and enhanced in vivo antitumor efficacy, Bioconjug Chem. 16 (2005) 122-130.

52. M. Harada, I. Bobe, H. Saito, N. Shibata, R. Tanaka, T. Hayashi, Y. Kato, Improved antitumor activity of stabilized anthracycline polymeric micelle formulation, NC-6300, Cancer Sci. 102 (2011) 192-199.

53. A. Takahashi, Y. Yamamoto, M. Yasunaga, Y. Koga, J. Kuroda, M. Takigahira, M. Harada, H. Saito, T. Hayashi, Y. Kato, T. Kinoshita, N. Ohkohchi, I. Hyodo, Y. Matsumura, NC6300 , an epirubicin-incorporating micelle, extends the antitumor effect and reduces the cardiotoxicity of epirubicin, Cancer Sci. 104 (2013) 920-925.

54. E. Wong, C.M. Giandomenico, Current status of platinum-based antitumor drugs, Chemical Rev. 99 (1999) 2451-2466.

55. A. Grothey, R.M. Goldberg, A review of oxaliplatin and its clinical use in colorectal cancer, Exp. Op. Pharmacother. 5 (2004) 2159-2170.

56. H.S. Oberoi, N.V. Nukolova, A.V. Kabanov, T.K. Bronich, Nanocarriers for delivery of platinum anticancer drugs, Adv. Drug Deliv. Rev. 65(2013) 1667-1685.

57. N. Nishiyama, S. Okazaki, H. Cabral, M. Miyamoto, Y. Kato, Y. Sugiyama, K. Nishio, Y. Matsumura, K. Kataoka, Novel cisplatin-incorporated polymeric micelles can eradicate solid tumors in mice, Cancer Res. 63(2003) 8977-8983.

58. H. Cabral, N. Nishiyama, S. Okazaki, H. Koyama, K. Kataoka, Preparation and biological properties of dichloro (1, 2-diaminocyclohexane) platinum (II)(DACHPt)-loaded polymeric micelles, J. Control. Release, 101 (2005) 223-232.

59. M. Yokoyama, T. Okano, Y. Sakurai, S. Suwa, K. Kataoka, Introduction of cisplatin into polymeric micelle. J. Contr. Rel. 39 (1996) 351-356.

60. N. Nishiyama, M. Yokoyama, T. Aoyagi, T. Okano, Y. Sakurai, K. Kataoka, Preparation and characterization of self-assembled polymer-metal complex micelle from cisdichlorodiammineplatinum(II) and poly(ethylene glycol)-poly(aspartic acid) block copolymer in an aqueous medium, Langmuir 15 (1999) 377-383

61. N. Nishiyama, Y. Kato, Y. Sugiyama, K. Kataoka, Cisplatin-loaded polymer-metal complex micelle with time-modulated decaying property as a novel drug delivery system, Pharm. Res., 18 (2001) 1035-1041.

62. Y. Mochida, H. Cabral, Y. Miura, F. Albertini, S. Fukushima, K. Osada, N. Nishiyama, K. Kataoka, Bundled Assembly of Helical Nanostructures in Polymeric Micelles Loaded with Platinum Drugs Enhancing Therapeutic Efficiency against Pancreatic Tumor, ACS Nano (2014) under revision.

63. H. Uchino, Y. Matsumura, T. Negishi, F. Koizumi, T. Hayashi, T. Honda, N. Nishiyama, K. Kataoka, S. Naito, T. Kakizoe, Cisplatin-incorporating polymeric micelles (NC-6004) can reduce nephrotoxicity and neurotoxicity of cisplatin in rats, Br. J. Cancer 93 (2005) 678-687.

64. M. Baba, Y. Matsumoto, A. Kashio, H. Cabral, N. Nishiyama, K. Kataoka, T. Yamasoba, Micellization of cisplatin (NC-6004) reduces its ototoxicity in guinea pigs, J. Control. Release 157 (2012) 112-117.

65. R. Plummer, R. Wilson, H. Calvert, A. Boddy, M. Griffin, J. Sludden, M. Tilby, M. Eatock, D. Pearson, C. Ottley, A Phase I clinical study of cisplatin-incorporated polymeric micelles (NC-6004) in patients with solid tumours, Br. J. Cancer 104 (2011) 593-598.

66. W.-C. Su, L.-T. Chen, C.-P. Li, J.-S. Chen, Y.-L. Lin, S.-P. Choo, Y. Matsumura, Phase I/II study of NC-6004, a novel micellar formulation of cisplatin, in combination with gemcitabine in patients with pancreatic cancer in Asia - results of phase I, ESMO (2012) Abstract 863

67. H. Cabral, N. Nishiyama, K. Kataoka, Optimization of (1,2-diaminocyclohexane)platinum(II)-loaded polymeric micelles directed to improved tumor targeting and enhanced antitumor activity, J. Control. Release 121 (2007) 146-155.

68. M. Rafi, H. Cabral, M. Kano, P. Mi, C. Iwata, M. Yashiro, K. Hirakawa, K. Miyazono, N. Nishiyama, K. Kataoka, Polymeric micelles incorporating (1, 2-diaminocyclohexane) 
platinum (II) suppress the growth of orthotopic scirrhous gastric tumors and their lymph node metastasis, J. Control. Release 159 (2012) 189-196.

69. S. Deshayes, H. Cabral, T. Ishii, Y. Miura, S. Kobayashi, T. Yamashita, A. Matsumoto, Y. Miyahara, N. Nishiyama, K. Kataoka, Phenylboronic Acid-Installed Polymeric Micelles for Targeting Sialylated Epitopes in Solid Tumors, J. Am. Chem. Soc. 135 (2013) 15501-15507.

70. H. Cabral, M. Murakami, H. Hojo, Y. Terada, M.R. Kano, U.-i. Chung, N. Nishiyama, K. Kataoka, Targeted therapy of spontaneous murine pancreatic tumors by polymeric micelles prolongs survival and prevents peritoneal metastasis, Proc. Natl. Acad. Sci. U S A. 110 (2013) 11397-11402.

71. Y. Yamamoto, I. Hyodo, M. Takigahira, Y. Koga, M. Yasunaga, M. Harada, T. Hayashi, Y. Kato, Y. Matsumura, Effect of combined treatment with the epirubicin-incorporating micelles (NC-6300) and 1,2-diaminocyclohexane platinum (II)-incorporating micelles (NC4016) on a human gastric cancer model, Int. J. Cancer (2013) doi: 10.1002/ijc.28651

72. T.M. Allen, Ligand-targeted therapeutics in anticancer therapy, Nat. Rev. Cancer 2 (2002) 750-763.

73. V. Torchilin, Antibody-modified liposomes for cancer chemotherapy, Expert Opin. Drug Deliv. 5 (2008) 1003-1025

74. W.W. Cheng, T.M. Allen, The use of single chain Fv as targeting agents for immunoliposomes: an update on immunoliposomal drugs for cancer treatment, Expert Opin. Drug Deliv. 7 (2010) 461-478.

75. O.C. Farokhzad, J. Cheng, B.A. Teply, I. Sherifi, S. Jon, P.W. Kantoff, J.P. Richie, R. Langer, Targeted nanoparticle-aptamer bioconjugates for cancer chemotherapy in vivo, Proc Natl Acad Sci U S A. 103 (2006) 6315-6320.

76. M. Oba, Y. Vachutinsky, K. Miyata, M.R. Kano, S. Ikeda, N. Nishiyama, K. Itaka, K. Miyazono, H. Koyama, K. Kataoka, Antiangiogenic gene therapy of solid tumor by systemic injection of polyplex micelles loading plasmid DNA encoding soluble flt-1, Mol. Pharm. 7 (2010) 501-509.

77. Y. Miura, T. Takenaka, K. Toh, S. Wu, H. Nishihara, M. R. Kano, Y. Ino, T. Nomoto, Y. Matsumoto, H. Koyama, H. Cabral, N. Nishiyama, K. Kataoka, Cyclic RGD-linked polymeric micelles for targeted delivery of platinum anticancer drugs to glioblastoma through the blood-brain tumor barrier, ACS Nano 7 (2013) 8583-8592.

78. Y. Bae, W.D. Jang, N. Nishiyama, S. Fukushima, K. Kataoka, Multifunctional polymeric micelles with folate-mediated cancer cell targeting and $\mathrm{pH}$-triggered drug releasing properties for active intracellular drug delivery, Mol Biosyst. 1 (2005) 242-250.

79. E. Ruoslahti, RGD and other recognition sequences for integrins, Annu. Rev. Cell Dev. Biol. 12 (1996) 697-715.

80. M. Pfaff, K. Tangemann, B. Müller, M. Gurrath, G. Müller, H. Kessler, R. Timpl, J. Engel, Selective recognition of cyclic RGD peptides of NMR defined conformation by alpha IIb beta 3, alpha V beta 3, and alpha 5 beta 1 integrins, J. Biol. Chem. 269 (1994) 20233-20238.

81. E. Koivunen, B. Wang, E. Ruoslahti, Phage libraries displaying cyclic peptides with different ring sizes: ligand specificities of the RGD-directed integrins, Nat. Biotechnol 13 (1995) 265-270.

82. D.R. Groothuis, The blood-brain and blood-tumor barriers: A review of strategies for increasing drug delivery, Neuro-Oncol.2 (2000) 45-59.

83. A. Harada, K. Kataoka, Chain length recognition: core-shell supramolecular assembly from oppositely charged block copolymers, Science 283 (1999) 65-67.

84. K. Kataoka, H. Togawa, A. Harada, K. Yasugi, T. Matsumoto, S. Katayose, Spontaneous formation of polyion complex micelles with narrow distribution from antisense oligonucleotide and cationic block copolymer in physiological saline, Macromol. 29 (1996) 8556-8557.

85. S. Katayose, K. Kataoka, Water-soluble polyion complex associates of DNA and poly(ethylene glycol)-poly(L-lysine) block copolymer. Bioconjug. Chem. 8 (1997) 702-707. 
86. Y. Lee, T. Ishii, H. Cabral, H.J. Kim, H.J. Seo, N. Nishiyama, H. Oshima, K. Osada, K. Kataoka, Charge-conversional PIC micelles - an efficient protein delivery nanocarrier into cytoplasm, Angew. Chem. Int. Ed. 48 (2009) 5309-12.

87. K. Itaka, N. Kanayama, N. Nishiyama, W.D. Jang, Y. Yamasaki, K. Nakamura, H. Kawaguchi, K. Kataoka K. Supramolecular nanocarrier of siRNA from PEG-based block catiomer carrying diamine side chain with distinctive $\mathrm{pKa}$ directed to enhance intracellular gene silencing, J. Am. Chem. Soc. 126 (2004) 13612-13613.

88. S. Uchida, K. Itaka, H. Uchida, K. Hayakawa, T. Ogata, T. Ishii, S. Fukushima, K. Osada, K. Kataoka, In vivo messenger RNA introduction into the central nervous system using polyplex nanomicelle, PLoS One 8 (2013) e56220

89. H.R. Stapert, N. Nishiyama, D.-L. Jiang, T. Aida, K. Kataoka, Polyion complex micelles encapsulating light-harvesting ionic dendirmer zinc porphyrins, Langmuir 16 (2000) 8182 8188

90. T. Nomoto, Y. Matsumoto, K. Miyata, M. Oba, S. Fukushima, N. Nishiyama, T. Yamasoba, K. Kataoka, In situ quantitative monitoring of polyplexes and polyplex micelles in the blood circulation using intravital real-time confocal laser scanning microscopy, J. Control. Release 151(2011) 104-109.

91. Y. Kakizawa, A. Harada, K. Kataoka, Environment-sensitive stabilization of core-shell structured polyion complex micelle by reversible cross-linking of the core through disulfide bond, J Am Chem Soc, 121 (1999) 11247-11248

92. M. Oba, K. Miyata, K. Osada, R. J. Christie, M. Sanjoh, W. Li, S. Fukushima, T. Ishii, M. R. Kano, N. Nishiyama, H. Koyama, K. Kataoka, Polyplex micelles prepared from $\omega-$ cholesteryl PEG-polycation block copolymers for systemic gene delivery, Biomaterials 32 (2011) 652-663.

93. K. Miyata, N. Nishiyama, K. Kataoka, Rational design of smart supramolecular assemblies for gene delivery: Chemical challenges in the creation of artificial viruses, Chem. Soc. Rev. 41 (2012) 2562-2574.

94. M. Nakanishi, J. -S. Park, W. -D. Jang, M. Oba, K. Kataoka, Study of the quantitative aminolysis reaction of poly( $\beta$-benzyl L-aspartate) (PBLA) as a platform polymer for functionality materials, React. Funct. Polym. 67 (2007) 1361-1372.

95. N. Kanayama, S. Fukushima, N. Nishiyama, K. Itaka, W. -D. Jang, K. Miyata, Y. Yamasaki, U. -I. Chung, K. Kataoka, A PEG-based biocompatible block catiomer with high buffering capacity for the construction of polyplex micelles showing efficient gene transfer toward primary cells, ChemMedChem 1 (2006) 439-444.

96. H. Uchida, K. Miyata, M. Oba, T. Ishii, T. Suma, K. Itaka, N. Nishiyama, K. Kataoka, Oddeven effect of repeating aminoethylene units in the side chain of N-substituted polyaspartamides on gene transfection profiles, J. Am. Chem. Soc. 133 (2011) 15524-15532.

97. K. Itaka, T. Ishii, Y. Hasegawa, K. Kataoka, Biodegradable polyamino acid-based polycations as safe and effective gene carrier minimizing cumulative toxicity, Biomaterials 31 (2010) 3707-3714.

98. K. Itaka, S. Ohba, K. Miyata, H. Kawaguchi, K. Nakamura, T. Takato, U. -I. Chung, K. Kataoka, Bone regeneration by regulated in vivo gene transfer using biocompatible polyplex nanomicelles, Mol. Ther. 15 (2007) 1655-1662.

99. R. J. Christie, K. Miyata, Y. Matsumoto, T. Nomoto, D. Menasco, T. -C. Lai, M. Pennisi, K. Osada, S. Fukushima, N. Nishiyama, Y. Yamasaki, K. Kataoka, Effect of polymer structure on micelles formed between siRNA and cationic block copolymer comprising thiols and amidines, Biomacromol. 12 (2011) 3174-3185.

100. R. J. Christie, Y. Matsumoto, K. Miyata, T. Nomoto, S. Fukushima, K. Osada, J. Halnaut, F. Pittella, H. -J. Kim, N. Nishiyama, K. Kataoka, Targeted polymeric micelles for siRNA treatment of experimental cancer by intravenous injection, ACS Nano 6 (2012) 5174-5189. 
101. H.-J. Kim, T. Ishii, M. Zheng, S. Watanabe, K. Toh, Y. Matsumoto, N.Nishiyama, K.Miyata, K. Kataoka, Multifunctional polyion complex micelle featuring enhanced stability, targetability, and endosome escapability for systemic siRNA delivery to subcutaneous model of lung cancer, Drug Deliv. Transl. Res. 4 (2014) 50-60.

102. H. -J. Kim, M. Oba, F. Pittella, T. Nomoto, H. Cabral, Y. Matsumoto, K. Miyata, N. Nishiyama, K. Kataoka, PEG-detachable cationic polyaspartamide derivatives bearing stearoyl moieties for systemic siRNA delivery toward subcutaneous BxPC3 pancreatic tumor, J. Drug Target. 20 (2012) 33-42

103. H. Shimizu, Y. Hori, S. Kaname, K. Yamada, N. Nishiyama, S. Matsumoto, K. Miyata, M. Oba, A. Yamada, K. Kataoka, T. Fujita, siRNA-based therapy ameliorates glomerulonephritis, J. Am. Soc. Nephrol. 21 (2010) 622-633.

104. Y. Kakizawa, K. Kataoka, Block copolymer self-assembly into monodispersive nanoparticles with hybrid core of antisense DNA and calcium phosphate, Langmuir 18 (2002) 4539-4543.

105. Y. Kakizawa, S. Furukawa, K. Kataoka, Block copolymer-coated calcium phosphate nanoparticles sensing intracellular environment for oligodeoxynucleotide and siRNA delivery, J. Control. Release 97 (2004) 345-356.

106. Y. Kakizawa, S. Furukawa, A. Ishii, K. Kataoka, Organic-inorganic hybridnanocarrier of siRNA constructing through the self-assembly of calcium phosphate and PEG-based block aniomer, J. Control. Release 111 (2006) 368-370.

107. M. Zhang, A. Ishii, N. Nishiyama, S. Matsumoto, T. Ishii, Y. Yamasaki, K. Kataoka, PEGylated calcium phosphate nanocomposites as smart environment-sensitive carriers for siRNA delivery, Adv. Mater. 21 (2009) 3520-3525.

108. F. Pittella, K. Miyata, Y. Maeda, T. Suma, S. Watanabe, Q. Chen, R. J. Christie, K. Osada, N. Nishiyama, K. Kataoka, Pancreatic cancer therapy by systemic administration of VEGF siRNA contained in calcium phosphate/charge-conversional polymer hybrid nanoparticles, J. Control. Release 161 (2012) 868-874.

109. F. Pittella, H. Cabral, Y. Maeda, P. Mi, S. Watanabe, H. Takemoto, H. -J. Kim, N. Nishiyama, K. Miyata, K. Kataoka, Systemic siRNA delivery to a spontaneous pancreatic tumor model in transgenic mice by PEGylated calcium phosphate hybrid micelles, J. Control. Release 178 (2014) 18-24.

110. P. Mi, D. Kokuryo, H. Cabral, M. Kumagai, T. Nomoto, I. Aoki, Y. Terada, A. Kishimura, N. Nishiyama, K. Kataoka, Hydrothermally synthesized PEGylated calcium phosphate nanoparticles incorporating Gd-DTPA for contrast enhanced MRI diagnosis of solid tumors, J. Control. Release 174 (2014) 63-71

111. H. Cabral, N. Nishiyama, K. Kataoka, Supramolecular nanodevices: From design validation to theranostic nanomedicine, Acc. Chem. Res. 44 (2011) 999-1008.

112. S. Kaida, H. Cabral, M. Kumagai, A. Kishimura, Y. Terada, M. Sekino, I. Aoki, N. Nishiyama, T. Tani, K. Kataoka, Visible drug delivery by supramolecular nanocarriers directing to single-platformed diagnosis and therapy of pancreatic tumor model, Cancer Res. 70 (2010) 7031-7041.

113. K. Ikeda, M. Terashima, H. Kawamura, I. Takiyama, K. Koeda, A. Takagane, N. Sato, K. Ishida, T. Iwaya, C. Maesawa, H. Yoshinari, K. Saito, Pharmacokinetics of Cisplatin in Combined Cisplatin and 5-Fluorouracil Therapy: A Comparative Study of Three Different Schedules of Cisplatin Administration, Jpn. J. Clin. Oncol. 28 (1998) 168-175.

114. P.A. Reece, I. Stafford, R.L. Abbott, C. Anderson, J. Denham, S. Freeman, R.G. Morris, P.G. Gill, C.L. Olweny, Two- versus 24-hour infusion of cisplatin: pharmacokinetic considerations, J. Clin. Oncol. 7 (1989) 270-275. 


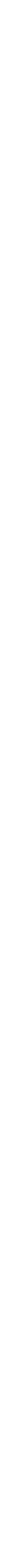

